\title{
Characterization and Functional Assessment of Endothelial Progenitor Cells in Ischemic Stroke Patients
}

\author{
Marek Kukumberg ${ }^{1}$ • Aung Moe Zaw ${ }^{2}$ - Daniel H. C. Wong ${ }^{1,3} \cdot$ Chin Min Toh $^{3}$ • Bernard P. L. Chan ${ }^{4}$. \\ Raymond C. S. Seet ${ }^{4,5}$ • Peter T. H. Wong ${ }^{3}$ • Evelyn K. F. Yim ${ }^{1,2,6,7}$ (D)
}

Accepted: 19 October 2020 / Published online: 10 November 2020

(C) Springer Science+Business Media, LLC, part of Springer Nature 2020

\begin{abstract}
Endothelial dysfunction has been implicated in atherosclerosis, ischemic heart disease, and stroke. Endothelial progenitor cells (EPCs), found in the bone marrow and peripheral blood as rare cell population, demonstrated a high proliferation and differentiation capacity. Understanding how such diseases influence the quantity and functionality of EPCs is essential for the development of novel therapies. This study aims to investigate the factors that affect the quantity and functionality of circulating EPCs in stroke patients and healthy controls. Blood samples were collected once from healthy donors $(n=30)$ and up to 3 times (within 7 days (baseline), 3 and 12 months post-stroke) from stroke patients $(n=207)$. EPC subpopulations were isolated with flow cytometry for characterization. The Matrigel tubular formation assay was performed as a measure of functionality. An increased amount of circulating EPCs was observed in stroke patients over 45 years when compared to age-matched healthy individuals. EPCs showed a rising trend in stroke patients over the 12-month post-stroke period, reaching statistical significance at 12 months post-stroke. Isolated $\mathrm{CD} 34^{+} \mathrm{KDR}^{+}$cells from stroke patients showed impairment in tubular formation capability when compared to cells from healthy donors. The quantity and vasculogenic function of circulating EPCs in peripheral blood have been effectively evaluated in stroke patients and healthy control donors in this study. Age and stroke are found to be 2 influencing factors on the angiogenic capacity. It is suggested that the increase in EPC number is triggered by the recovery response following ischemic stroke.
\end{abstract}

Keywords Endothelial progenitor cells $\cdot$ Ischemic stroke $\cdot$ Matrigel assay $\cdot$ Tubular formation $\cdot$ Flow cytometry $\cdot$ Vasculogenic function

\section{Introduction}

Ischemic stroke (IS) is one of the vascular diseases that are being studied with strong interest. IS, also termed as cerebral

Marek Kukumberg and Aung Moe Zaw contributed equally to this work.

Supplementary Information The online version contains supplementary material available at https://doi.org/10.1007/s12015-02010064-z.

Evelyn K. F. Yim

eyim@uwaterloo.ca

1 Mechanobiology Institute, National University of Singapore, \#05-01 T-lab, 5A Engineering Drive 1, Singapore 117411, Singapore

2 Department of Chemical Engineering, University of Waterloo, 200 University Avenue West, Waterloo, Ontario N2L 3G1, Canada

3 Department of Pharmacology, Yong Loo Lin School of Medicine, National University of Singapore, 16, Medical Drive, \#04-01, Singapore 117600, Singapore infarction, is defined as local blood supply obstruction leading to cerebral anoxia, ischemic necrosis and subsequent apoptotic cell death accompanied by the loss of neurological functions [1]. Most IS are triggered by atherosclerosis, which is 
caused by endothelial dysfunction (EDF) affecting the inner layer of vessels [2-4]. The causative factor and/or promoting mechanism of atherosclerosis is the effective reduction of nitric oxide (NO) availability, and it requires an early therapeutic intervention for the recovery of EDF. EDF therapy includes 1) the use of pharmacological drugs, such as beta blockers, calcium channel blockers, erythropoietin, renin-angiotensin inhibitors [5, 6] and/or 2) a non-pharmacological therapy approach in the form of lifestyle changes such as aerobic exercise and healthy diet [7]. IS has been shown to have a higher prevalence and mortality in Asian countries when compared with the rest of the world with unclear reasons [8-10]. Thus the interest to identify a biomarker and potential therapy is high [11]. It was proposed that endothelial progenitor cells (EPCs) play a major role in the revascularization of the ischemic cerebral tissue and participate in the repair [9].

EPCs are a small population of circulating cells with the potential for vascular damage repair, and they have been identified in bone marrow and peripheral blood [12]. The rare cell population (0.01-0.001\% in peripheral blood) showed various functions and properties of vascular endothelial cells and additionally, demonstrated high proliferation and differentiation capability [12-14]. Furthermore, the EPCs express various cell surface markers similar to those expressed by vascular endothelial cells. Various combinations of surface markers have been used to characterize different populations of EPCs, and studies have shown different cell subpopulations with distinct characteristics and functionality [15-17]. One of the characteristic cell marker combination for EPCs in bone marrow, circulating blood and spleen was defined as $\mathrm{CD} 34^{+} \mathrm{CD} 133^{+} \mathrm{KDR}^{+}$cell population [18-20]. Besides the characterization of EPCs in healthy individuals, there has been an interest to investigate the characteristics of EPCs in patients with different diseases [21-24]. Few studies have examined the correlation of the health status to the quantity of EPCs and their functionality $[25,26]$. To date, only one study could show a prognostic potential of EPCs, and overall, the prognostic significance of EPCs is still not fully understood [27].

Moreover, EPCs have been documented as a potential candidate for regenerative medicine and potential biomarker for vascular diseases including stroke [28, 29]. Hence, characterization of EPCs in healthy and diseased individuals is needed to investigate the correlations between demographical background and various risk factors.

In this study, it is hypothesized that the quantity and the functionality of circulating EPCs in peripheral blood varies with age and health status. This study aims to characterize the EPCs based on their developmental stage as early and late EPCs in healthy individuals and stroke patients aged 2087 years. Additionally, the influence of demographic parameters (age, sex and ethnicity) and selected risk factors on the amount of circulating EPCs will be investigated. Functionality of EPCs of healthy individuals and stroke patients will be compared in term of vasculogeneity with an in vitro Matrigel tubular formation assay.

\section{Material and Methods}

\section{Study Population}

The study was conducted in accordance with the guidelines on good clinical practice and with the ethical standards for human experimentation established by the Declaration of Helsinki. The study protocol was reviewed and approved by the Institutional Review Board, National Healthcare Group, Singapore (IRB \#2011/01750). The study enrolled 237 subjects with the collection of demographic information between October 2011 and October 2015. All subjects gave written consent before being included in the study. Healthy donors were included in the study with the following criteria: no history of previous stroke and/or vascular disease while stroke patients were included in the study with recent history of a stroke and/or transient ischemic attack (TIA) with or without a determined etiology. Blood samples were collected only once from healthy donors, while stroke donors had samples collected at up to 3 time points. The first time point (baseline, BL) was defined as a time point within 7 days post stroke and the start of the study, followed by 3 months (M3) and 12 months (M12) time points after the onset of stroke and/or transient ischemic attack (TIA). Time points for sample collection were scheduled and performed with the routine clinical visits for post-stroke management standardized by the National University Hospital. During the study, only the practitioners involved in collecting the samples had the bio-data and the sample identity. The researchers who processed the blood samples, performed the flow cytometry and subsequent analysis were blinded from sample identity.

\section{Blood Collection and Processing}

Samples were collected as venous blood in heparin-coated vials in a volume of $10 \mathrm{~mL}$ and $20 \mathrm{~mL}$ from stroke patients and healthy donors, respectively. The first $5 \mathrm{~mL}$ was not used for EPC isolation. The blood samples were processed as previously described [30]. Briefly, the samples were carefully layered over Ficoll paque (GE Life Sciences) prior to centrifugation. The mononuclear cell fraction was aspirated and mixed with Roswell Park Memorial Institute medium (RPMI, Gibco) followed by another centrifugation step. The cell pellet was stored in a solution composed of fetal bovine serum (FBS, HyClone, GE Healthcare Life Sciences) and $10 \%$ dimethyl sulfoxide (DMSO) in $-80{ }^{\circ} \mathrm{C}$ freezer for slow-freezing and then stored in the vapor phase of liquid nitrogen tank before analysis. 


\section{Flow Cytometric Evaluation of Endothelial Progenitor Cell Markers}

All experiments were performed with the approval of the Institutional Biosafety Committee, National University of Singapore (NUS). For evaluation of endothelial progenitor cell markers - CD34, CD133 and KDR, the cell pellet was thawed and resuspended in $1000 \mu \mathrm{L}$ solution containing $1 \mathrm{X}$ PBS (pH 7.2), 0.5\% bovine serum albumin (BSA, Santa Cruz Biotechnology), and $2 \mathrm{mM}$ EDTA (flow buffer). The cell suspension was divided equally into tubes to contain $100 \mu \mathrm{L}$ of suspension in each tube and processed with a lysis buffer (10 $\mu \mathrm{L} /$ tube, RBC Lysis buffer, Miltenyi Biotec) and nonspecific Fc receptor-mediated antibody binding blocker (10 $\mu \mathrm{L} /$ tube, FcR blocking reagent, Miltenyi Biotec) prior to fluorescent labeling. Cells were incubated for $10 \mathrm{~min}$, washed with flow buffer, centrifuged and resuspended in flow buffer so that each tube contained $100 \mu \mathrm{L}$ of cell suspension. Cell suspension was labeled with fluorescently conjugated antibodies (Miltenyi Biotec): for triple staining with $10 \mu \mathrm{L}$ each of following antibodies: CD34- FITC, CD133-PE, and KDR-APC. Fluorescence minus one (FMO) controls (10 $\mu \mathrm{L} /$ tube) were prepared as a mixture of two fluorochromes except the one being measured. IgG2a-FITC, IgG1-PE and IgG1-APC (10 $\mu \mathrm{L} /$ tube, Miltenyi Biotec) were used as isotype secondary controls. After incubation for $10 \mathrm{~min}$, cells were washed with flow buffer, centrifuged and fixed with $0.8 \%$ PFA according to the supplier's protocol. Flow cytometry was performed with the BD (Becton-Dickinson) LSR FortessaTM Flow Cytometry analyser. An assessment of $1 \times 10^{6}$ events per sample was considered to be sufficient for statistical analysis. Data was analyzed with FlowJo ${ }^{\text {TM }}$ (FlowJo 10.0.7v2) using the $1 \%$ gating method against FMO and isotype controls. The results were presented as a comparison of single-, double- and triple-marker expression.

\section{Evaluation of EPC Functionality with Matrigel Tubular Formation Assay In Vitro}

To assess the vascular repair function of EPCs, a Matrigel tubular formation assay in vitro was performed in samples collected from healthy donors $(n=8)$ at one time point and stroke patients $(n=10)$ at BL and/or M3 time point. All subjects were randomly selected. The EPCs comprise of two subpopulations that have distinct and different functionality [16], and hence the angiogenic $\mathrm{CD} 34^{+} \mathrm{KDR}^{+}$cell subpopulation, also termed as late EPCs, was selected for the functional evaluation. However, due to low quantity of EPCs in peripheral blood and the inability to form tube structures by itself in the Matrigel, a co-culture of EPCs with human umbilical vein endothelial cells (HUVECs) was performed.

\section{HUVECs Cell Culture}

Human umbilical vein endothelial cells (HUVECs, Lonza, passage 4) were expanded for approximately 3-4 days in endothelial growth media (EGM-2MV, Lonza), according to supplier's protocol at 5000 cells $/ \mathrm{cm}^{2}$ seeding density. The cells were maintained in an incubator at $37{ }^{\circ} \mathrm{C}$ with stable $5 \% \mathrm{CO}_{2}$, and the medium was changed every other day. To obtain the cells from culture, HUVECs were trypsinized and harvested according to manufacturer's instructions.

\section{Fluorescence Activated Cell Sorting of CD34 ${ }^{+} \mathrm{KDR}^{+}$ Cell Population}

Blood samples were collected from healthy donors $(n=8)$ once whereby from stroke patients $(n=10)$ at BL and/or M3 time point. The samples were processed as described above. For the evaluation of EPC functionality in the Matrigel tubular formation assay, mononuclear cells from the peripheral blood were stained in a similar process as described in flow cytometry preparation without the fixation step. Fluorescence activated cell sorting (FACS) of live cells was performed with FACSAria II (Becton-Dickinson). The $\mathrm{CD}^{+} 4^{+} \mathrm{KDR}^{+}$cell population was collected in endothelial basal medium (EBM-2, Lonza) supplemented with 3\% FBS (EBM-F).

\section{Matrigel Tubular Formation Assay In Vitro}

The tubular formation capability was evaluated by conducting a Matrigel tubular formation assay in vitro. Matrigel (BD Matrigel ${ }^{\mathrm{TM}}$ Basement Membrane Matrix, BD Biosciences, $10 \mu \mathrm{L}$ per well) was placed in a 15 well $\mu$-slide ( $\mu$-slide Angiogenesis, Ibidi) and incubated for one hour at $37{ }^{\circ} \mathrm{C}$. The HUVECs and $\mathrm{CD} 34^{+} \mathrm{KDR}^{+}$cells were cultured in three types of media (Table 1): (1) EGM-2MV; (2) endothelial basal medium (EBM) with reduced 3\% FBS and supplemented with $10 \mathrm{ng} / \mathrm{ml}$ vascular endothelial growth factor (VEGF, Gibco) (EBM-FV) and (3) EBM with reduced 3\% FBS (EBM-F). To evaluate the influence of $\mathrm{CD} 34^{+} \mathrm{KDR}^{+}$cell population on the tubular formation capability of HUVECs, cells were cultured in following groups: (1) HUVECs only in EGM-2MV; (2) HUVECs only in EBM-FV; (3) HUVECs only in EBM-F as positive controls; and (4) HUVECs and $\mathrm{CD} 34^{+} \mathrm{KDR}^{+}$cell population co-culture in a ratio 2:1 in EBM-F. Cells were seeded in a density of 3000 cells per well. Cells were cultured for $20 \mathrm{~h}$ and stained with calcein AM (Life Technologies) as previously described [31] (Table 1).

\section{Imaging and Evaluation}

The $\mu$-slides were imaged with epifluorescence microscope (Leica DMi8) equipped with Q-imaging camera and Q Capture Pro software. During the imaging process, all 
Table 1 Medium compositions. Medium compositions and labels utilized in the co-culture assay

\begin{tabular}{ll}
\hline Medium compositions and labels \\
\hline $\begin{array}{l}\text { Medium } \\
\text { label }\end{array}$ & Medium compositions \\
\hline EGM-2MV & $\begin{array}{c}\text { Endothelial basal medium (EBM-2) supplemented with 5\% fetal bovine serum and the proprie- } \\
\text { tary undisclosed quantities of vascular endothelial growth factor (VEGF), hydrocortisone, } \\
\text { gentamicin, amphotericin-B, ascorbic acid, human epidermal growth factor (hEGF), human } \\
\text { fibroblastic growth factor (hFGF-B) and Insulin-like growth factor 1 ( }{ }^{3} \text {-IGF-1) }\end{array}$ \\
EBM-FV & $\begin{array}{l}\text { Endothelial basal medium (EBM-2) supplemented with 3\% fetal bovine serum and } 10 \mathrm{ng} / \mathrm{ml} \\
\text { VEGF } \\
\text { Endothelial basal medium (EBM-2) supplemented with 3\% fetal bovine serum }\end{array}$ \\
\hline
\end{tabular}

acquisition parameters were maintained the same. The images were taken at 10x magnification processed with Metamorph Microscopy Automation and Image Analysis Software (v7.8, Molecular Devices).

\section{Data and Statistical Analysis}

The patient samples and flow cytometry analyses were performed as blinded analyses. The collection of the blood samples and demographical data were performed separately from the sample and data analyses. Researchers performed the flow cytometry analyses were blinded from the demographical data until all sample collection and analyses had been completed. Statistical analysis was performed using a one-way and twoway ANOVA test with Tukey's post-hoc test using Prism (GraphPad). The principal component analysis (PCA) was performed using JMP statistical software. All values were presented as mean values \pm standard deviation. Statistical tests were considered significant when $p \leq 0.05$ (noted as one asterisk), $p \leq 0.01$ (noted as two asterisks), $p \leq 0.001$ (noted as three asterisks) and $p \leq 0.0001$ (noted as four asterisks).

\section{Results}

\section{Study Population and Safety}

Blood samples of 237 subjects ( 30 healthy donors, 207 stroke patients) were collected with standard demographical data and the following risk factors for stroke patients were considered for evaluation (Table 2): (1) atrial fibrillation, (2) ischemic heart disease, (3) hypertension, (4) diabetes mellitus, (5) hyperlipidemia, (6) previous stroke and/or TIA, (7) smoking, current or within 6-months prior stroke or TIA and (8) body mass index (BMI) for overweight and obesity calculation (Table 2).

To evaluate the amount of circulating EPCs post stroke, the amount of EPCs at three time points were quantified: baseline (BL; defined as a time point within 7 days post stroke and the start of the study), followed by 3 months (M3) and 12 months (M12) time points after the onset of stroke and/or transient ischemic attack (TIA).

Due to the variance in attendance by subjects for different time point of sample collection, samples were collected at the following time point combinations: (1) single time point $-\mathrm{BL}, \mathrm{M} 3$ or M12 $(n=53)$; (2) two time points $-\mathrm{BL}$ and $\mathrm{M} 3(n=57), \mathrm{M} 3$ and $\mathrm{M} 12(n=43), \mathrm{BL}$ and M12 $(n=6)$; (3) three time points $(n=48)$.

\section{Characterization of Endothelial Progenitor Cell Markers}

Quantification of the circulating EPCs in the peripheral blood was performed by the evaluation of the characteristic combination of the EPC cell markers - CD34, CD133 and KDR as

Table 2 Demographic data of healthy donors and stroke patients. Standard demographic data and risk factors indicated

Demographics and risk factors

\begin{tabular}{lll}
\hline Variable & Healthy donors & Stroke patients \\
\hline Subjects & 30 & 207 \\
Age (mean, SD) & $51 \pm 17$ & $58.7 \pm 10.3$ \\
Sex (\% male) & 50 & 69.1 \\
Ethnic groups (\%) & & \\
Chinese & 64.3 & 68.6 \\
Malay & 7.1 & 19.3 \\
Indian & 10.7 & 8.2 \\
Others & 17.9 & 3.9 \\
Risk factors (\%) & & \\
Atrial fibrillation & 0 & 5.8 \\
Ischemic heart disease & 0 & 6.8 \\
Hypertension & 25 & 59.4 \\
Diabetes mellitus & 10.7 & 38.2 \\
Hyperlipidemia & 21.4 & 80.7 \\
Previous stroke and/or TIA & 0 & 60.4 \\
Smoking, current or within 6 months & 14.3 & 34.8 \\
BMI for overweight/ obesity & 0 & 48.8 \\
\hline
\end{tabular}


$\mathrm{CD} 4^{+} \mathrm{CD} 133^{+} \mathrm{KDR}^{+}$cell population (Fig. 1a). Additionally, further analysis of two cell subpopulations, based on developmental stages [12-17], CD $34^{+} \mathrm{CD} 133^{+}$cells (termed as early EPCs, Fig. $1 \mathrm{~b}$ ) and $\mathrm{CD} 34^{+} \mathrm{KDR}^{+}$cells (termed as late EPCs, Fig. 1c) was performed. PCA analysis was also performed separately on stroke patients' EPCs and healthy donors' EPCs. The EPC cell population subsets in healthy donors' subsets were positively correlated with each other but no association with age was recognized (Supplementary Fig. 1A). In the stroke patients, the EPC cell population subsets within each time point were positively correlated with each other, but the population subsets at BL and M12 time points were found to be negatively correlated (Supplementary Fig. 1B).

All subjects were grouped based on their age. Defining age cut-off is challenging but based on previous studies, commonly defined "young adults" are individuals bellow 45 or 49 years $[32,33]$. Therefore, healthy subjects were grouped into groups of below 45 years old $(<45, n=12)$ and above or equal to 45 years of age $(\geq 45$, $n=18)$. The stroke patients group encompassed subjects of an age range 36 to 86 years $(n=207)$. Overall, the following trends were observed: The healthy donors below 45 years of age, showed the lowest EPC population represented by $\mathrm{CD} 34^{+} \mathrm{CD} 133^{+} \mathrm{KDR}^{+}$, and early $\mathrm{EPC}$ and late EPC subpopulations represented by $\mathrm{CD} 34^{+} \mathrm{CD} 133^{+}$ and $\mathrm{CD} 34^{+} \mathrm{KDR}^{+}$, respectively. The group of healthy donors above or equal to 45 years of age showed similar population level of the screened cell populations as the stroke patients at baseline time point (BL). Stroke patients at month 12 (M12) evaluation time point showed the highest amount of circulating $\mathrm{CD} 34^{+} \mathrm{CD} 133^{+} \mathrm{KDR}^{+}$ cell population, early EPCs and late EPCs subpopulations, and they were also significantly higher when compared to other stroke patient time points and healthy donor groups. Notably, the larger value distribution was observed in stroke patients regardless of the cell population and subpopulations, as well as regardless of the evaluation time points.

\section{Sex Influence Comparison}

Upon PCA analysis of healthy donors' EPC population subsets, the sex variable was not correlated with the EPC population subsets (Supplementary Fig. 2a). However, in the stroke patients, the male sex was found to be weakly correlated with M12 EPC subsets, while the female sex was found to be weakly correlated with BL EPC subsets (Supplementary Fig. 2B). The sex influence of healthy donors and stroke patients was also evaluated on the yield of $\mathrm{CD} 34^{+} \mathrm{CD} 133^{+} \mathrm{KDR}^{+}$cell population (Fig. 2a), early EPCs $\left(\mathrm{CD} 34^{+} \mathrm{CD} 133^{+}\right.$, Fig. 2b) and late EPCs $\left(\mathrm{CD} 34^{+} \mathrm{KDR}^{+}\right.$, Fig. 2c) subpopulations. No significant differences between sex groups were observed. However, both the male and female subjects showed the highest amount of $\mathrm{CD} 34^{+} \mathrm{CD} 133^{+} \mathrm{KDR}^{+}$cell population, early EPCs and late EPCs subpopulations at the M12 evaluation time point. Specifically, both male and female stroke patients showed a significant higher early EPCs $\left(\mathrm{CD} 34^{+} \mathrm{CD} 133^{+}\right)$population at M12 compared to other time points $(p<0.001)$; male patients showed a significant higher $\mathrm{CD} 34^{+} \mathrm{CD} 133^{+} \mathrm{KDR}^{+}$cell population and EPCs $\left(\mathrm{CD} 34^{+} \mathrm{KDR}^{+}\right)$population at $\mathrm{M} 12$ compared to other time points $(p<0.01)$.

\section{Age Subgroup Influence Comparison}

The PCA analysis showed that the EPC cell population subsets do not have strong correlation with age at stroke onset. A weak negative correlation of age at stroke onset and EPC population subsets at M12 was observed, although the contribution of age at stroke incident is low (3.5\% in principal component 1 and $0.01 \%$ in principal component 2, Supplementary Fig. 3A). However, within certain age groups, differences were observed between timepoints (Fig. 3a, b, c). Healthy donors and stroke patients were evaluated on the influence of age subgroups ranging from 20 to 90 years with a 10 years step on the
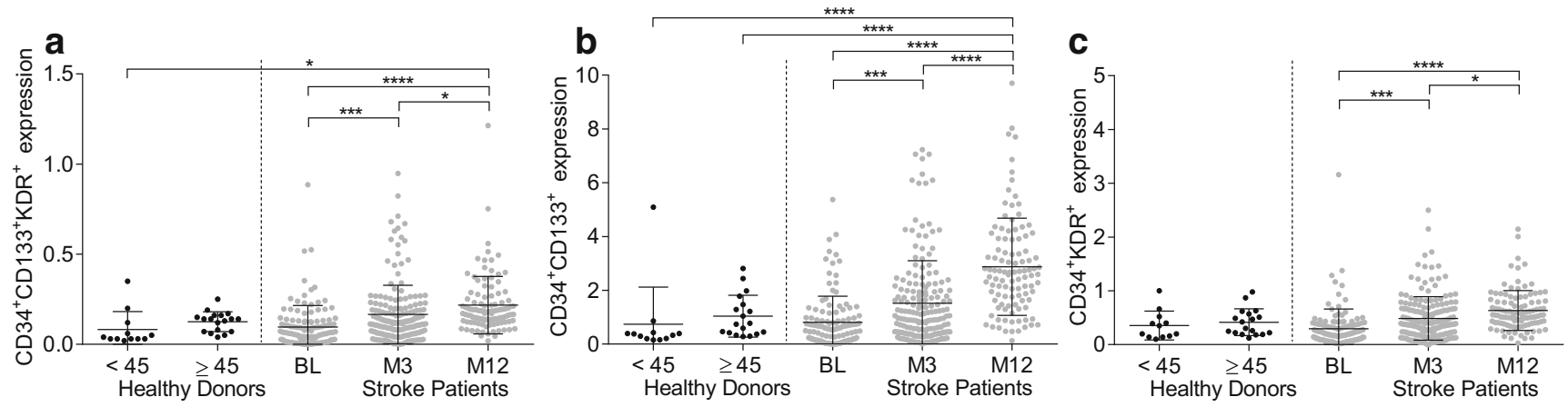

Fig. 1 Comparison of endothelial progenitor cell (EPC) marker expression quantified by flow cytometry. Comparison of cell populations represented by (a) $\mathrm{CD} 34^{+} 133^{+} \mathrm{KDR}^{+}$, and subpopulations represented by (b) $\mathrm{CD} 34^{+} 133^{+}$and (c) $\mathrm{CD} 34^{+} \mathrm{KDR}^{+}$between healthy donors grouped by

age and stroke patients grouped by evaluation time points: baseline (BL), month 3-time point (M3) and month 12 time point (M12). Data represent mean $\pm \mathrm{SD}, * p \leq 0.05, * * p \leq 0.01, * * * p \leq 0.001, * * * * p \leq 0.0001$ 


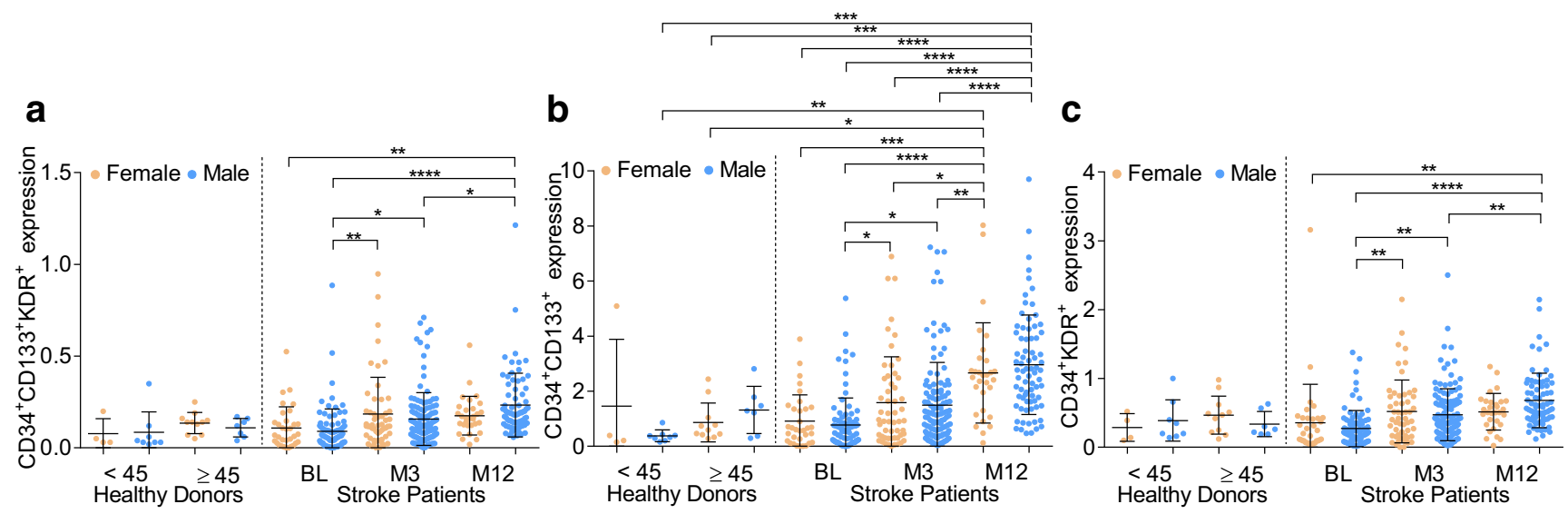

Fig. 2 Comparison of endothelial progenitor cell markers quantified by flow cytometry and grouped by sex. Comparison of (a) $\mathrm{CD} 4^{+} \mathrm{CD} 133^{+} \mathrm{KDR}^{+}$cell population, and subpopulations represented by (b) early EPCs $\left(\mathrm{CD} 34^{+} \mathrm{CD} 133^{+}\right.$cell subpopulation) and (c) late EPCs $\left(\mathrm{CD} 34^{+} \mathrm{KDR}^{+}\right.$cell subpopulation) between healthy donors

grouped by age and sex and stroke patients grouped by sex and evaluation time points: baseline (BL), month-3 time-point (M3) and month-12 time-point (M12). Data represent mean $\pm \mathrm{SD}, * p \leq 0.05$, ** $p \leq 0.01, * * * p \leq 0.001, * * * * p \leq 0.0001$

amount of $\mathrm{CD} 34^{+} \mathrm{CD} 133^{+} \mathrm{KDR}^{+}$cell population (Fig. 3a, Supplementary Fig. 3B), early EPCs $\left(\mathrm{CD} 34^{+} \mathrm{CD} 133^{+}\right.$, Fig. 3b, Supplementary Fig. 3C) and late EPCs (CD34 ${ }^{+} \mathrm{KDR}^{+}$, Fig. 3c, Supplementary Fig. 3D) subpopulations.

Significant differences were observed within 50-59, 60-69 and 70-79 year old age groups. The M12 evaluation time point, stroke patients showed the highest amount of $\mathrm{CD} 34^{+} \mathrm{CD} 133^{+} \mathrm{KDR}^{+}$cell population, early EPCs and late EPCs subpopulations (Fig. 3a, b, c). Interestingly, some of the $\mathrm{CD} 34^{+} \mathrm{CD} 133^{+} \mathrm{KDR}^{+}$cell populations, early EPCs $\left(\mathrm{CD} 34^{+} \mathrm{CD} 133^{+}\right)$and late EPCs $\left(\mathrm{CD} 34^{+} \mathrm{KDR}^{+}\right)$subpopulations in healthy control and in the different time points among stroke patients appeared to display the standard Gaussian distribution curves with age (Supplementary Fig. 3B, C and D).

\section{Ethnic Group Influence Comparison}

According to the PCA analysis, the contribution of the ethnic group variable was small, showing no significant correlation with any specific EPC subpopulations (Supplementary Fig. 4 A-E). Healthy donors and stroke patients were evaluated on the influence of ethnic groups on the amount of $\mathrm{CD} 34^{+} \mathrm{CD} 133^{+} \mathrm{KDR}^{+}$cell population (Fig. 4a and Supplementary Fig. 5A), early EPCs (CD $34^{+} \mathrm{CD} 133^{+}$, Fig. $4 \mathrm{~b}$ and Supplementary Fig. 5B) and late EPCs $\left(\mathrm{CD} 34^{+} \mathrm{KDR}^{+}\right.$, Fig. $4 \mathrm{c}$ and Supplementary Fig. 5C) subpopulations. No significant differences were observed between the cell populations from patients of the different ethnic groups.

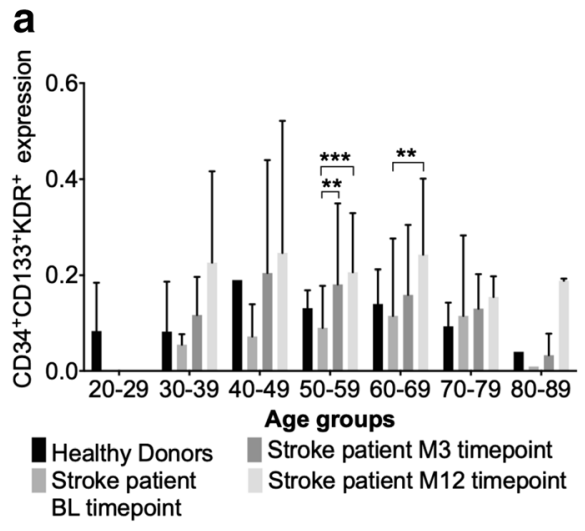

Fig. 3 Comparison of endothelial progenitor cell markers quantified by flow cytometry and grouped by age. Comparison of (a) $\mathrm{CD} 34^{+} \mathrm{CD} 133^{+} \mathrm{KDR}^{+}$cell population, (b) early EPCs $\left(\mathrm{CD} 34^{+} \mathrm{CD} 133^{+}\right.$ cell subpopulation) and (c) late EPCs $\left(\mathrm{CD} 34^{+} \mathrm{KDR}^{+}\right.$cell subpopulation) between healthy donors and stroke patients. Comparison of baseline b

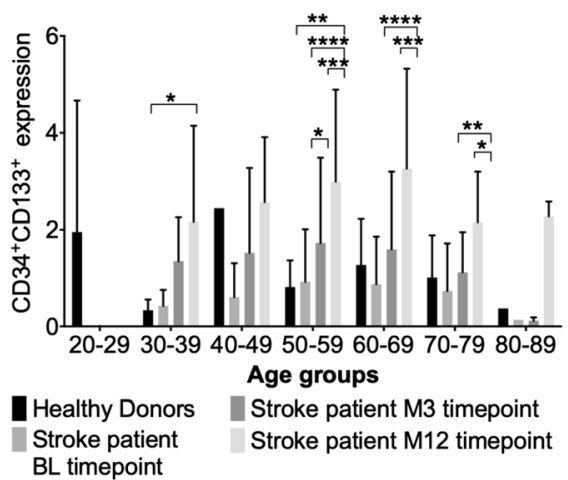

C

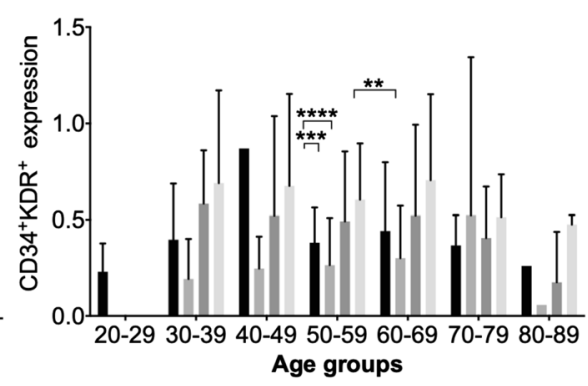

Healthy Donors Stroke patient M3 timepoint

Stroke patient Stroke patient M12 timepoint BL timepoint
(BL), month-3 time-point (M3) and month-12 time-point (M12) in age subgroups. Significant differences were observed within 50-59, 60-69 and 70-79 age groups. Data represent mean $\pm \mathrm{SD}, * p \leq 0.05$, ** $p \leq 0.01$, $* * * p \leq 0.001$, **** $p \leq 0.0001$ 


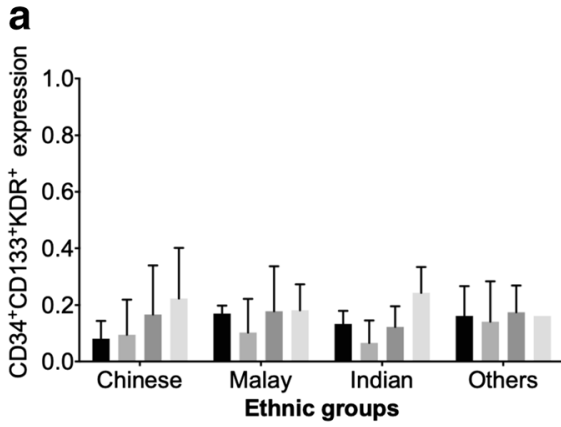

Healthy Donors Stroke patient M3 timepoint Stroke patient BL timepoint Stroke patient M12 timepoint

Fig. 4 Comparison of endothelial progenitor cell marker expression quantified by flow cytometry and grouped by ethnic groups. Comparison of (a) $\mathrm{CD} 34^{+} \mathrm{CD} 133^{+} \mathrm{KDR}^{+}$cell population, (b) early EPCs $\left(\mathrm{CD}_{3} 4^{+} \mathrm{CD} 133^{+}\right.$cell subpopulation) and (c) late EPCs

\section{Risk Factors and Influence Comparison}

PCA analysis of risk factors was evaluated. Parallel clusters observed in (Fig. 5a) could be due to the negative correlation between BMI and smoking history of the patients (Supplementary Fig. 6A). The patients with the same or similar BMI with or without smoking history clustered closely each other (Fig. 5a). Clusters with lower BMI are located in the lower half of the plot; while those with higher BMI clustered in the upper half of the plot, regardless of smoking history. Interestingly, while the correlations of the various risk factors were analyzed (Supplementary Fig. 6A), the two vectors of the following pairs of risk factors: BMI and hyperlipidemia, diabetes mellitus and hypertension, previous stroke and/or TIA and ischemic heart diseases are very close and, hence, they are positively correlated. In addition, upon observing the contribution of each variation in the PCA, diabetes mellitus (37\%) and previous stroke and/or TIA $(22 \%)$ are the two most important contributing variables for

a

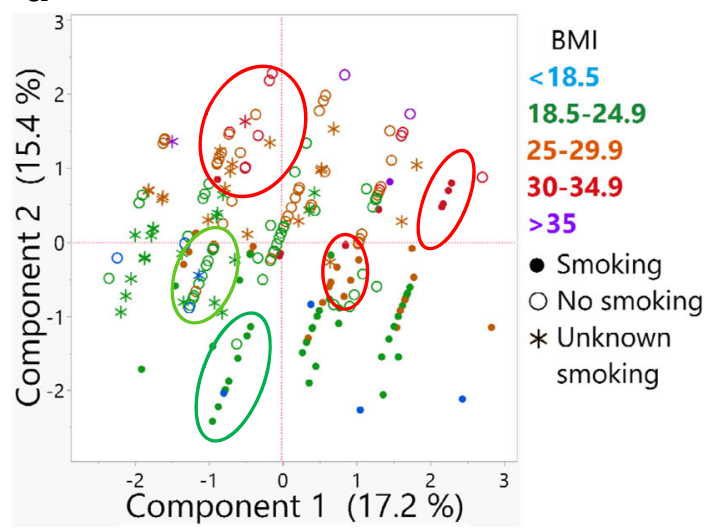

C

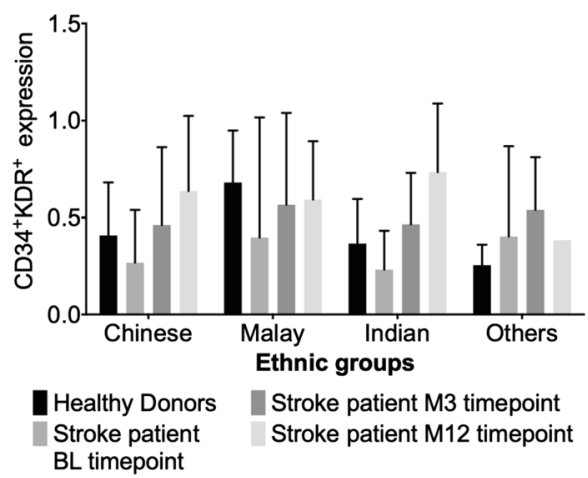

$\left(\mathrm{CD} 34^{+} \mathrm{KDR}^{+}\right.$cell subpopulation) between healthy donors and stroke patients. Comparison of baseline (BL), month-3 time-point (M3) and month-12 time-point (M12) in ethnic groups. Data represent mean \pm $\mathrm{SD}, * p \leq 0.05$

principal component 1; while BMI (39\%) and current or recent smoking within 6 months $(32 \%)$ are the two most important contributing variables for principal component 2. Among all risk factors, atrial fibrillation is the least contributing variable for both principal components $1(0.06 \%)$ and $2(0.02 \%)$ (Supplementary Fig. 6B). In the PCA analyses of the risk factors with the EPC subpopulations at different time points (Fig. 5b), diabetes mellitus was weakly correlated with M12 EPC populations, BMI was weakly correlated with BL EPC populations and hyperlipidemia was weakly correlated with M3 EPC population, while previous stroke and/or TIA was negatively correlated with BL EPC populations, and ischemic heart diseases was negatively correlated with M12 EPC populations. Principal component analysis of each risk factor and EPC subpopulations at different time points were provided in Supplementary Fig. 7A-H.

EPC subpopulations in stroke patients were also analyzed for the influence of each of the risk factors: diabetes mellitus (Fig. 6a-c), overweight $(25<\mathrm{BMI}<30)$ and obesity $(30<$

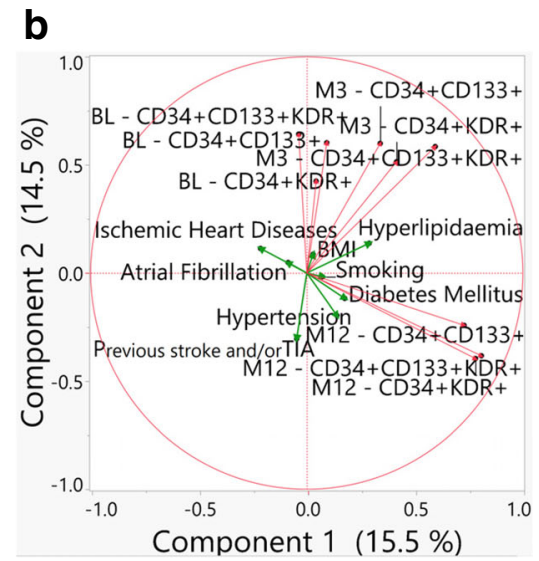

Fig. 5 Principal component analysis and comparison of endothelial progenitor cell marker expression. a) Score plot, and b) loading plot for the risk factors and EPC population subsets with comparison to $\mathrm{CD} 34^{+} \mathrm{CD} 133^{+} \mathrm{KDR}^{+}$population, early EPCs $\left(\mathrm{CD} 34^{+} \mathrm{CD} 133^{+}\right)$and late

EPCs $\left(\mathrm{CD} 34^{+} \mathrm{KDR}^{+}\right)$subpopulations between baseline (BL), month 3 time point (M3) and month 12 time point (M12) in stroke patients to risk factors 

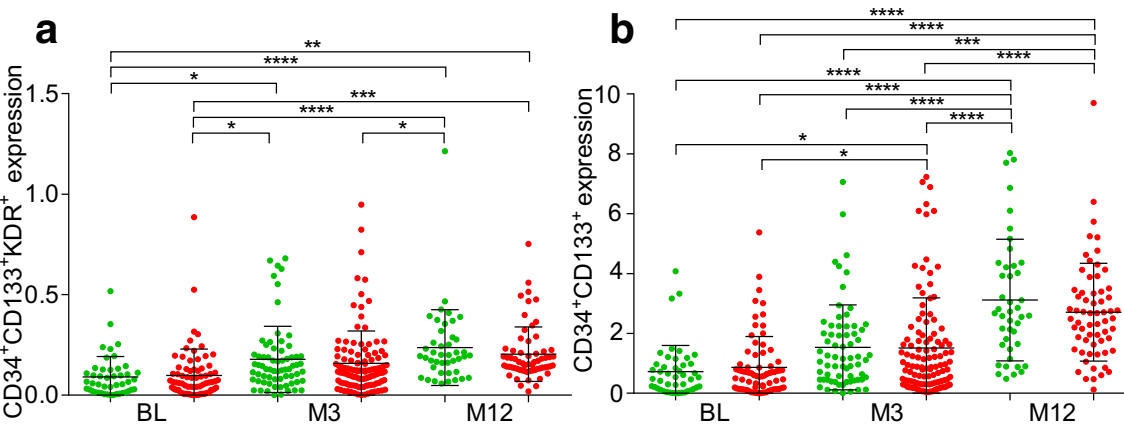

C

With diabetes mellitus Without diabetes mellitus

With diabetes mellitus Without diabetes mellitus
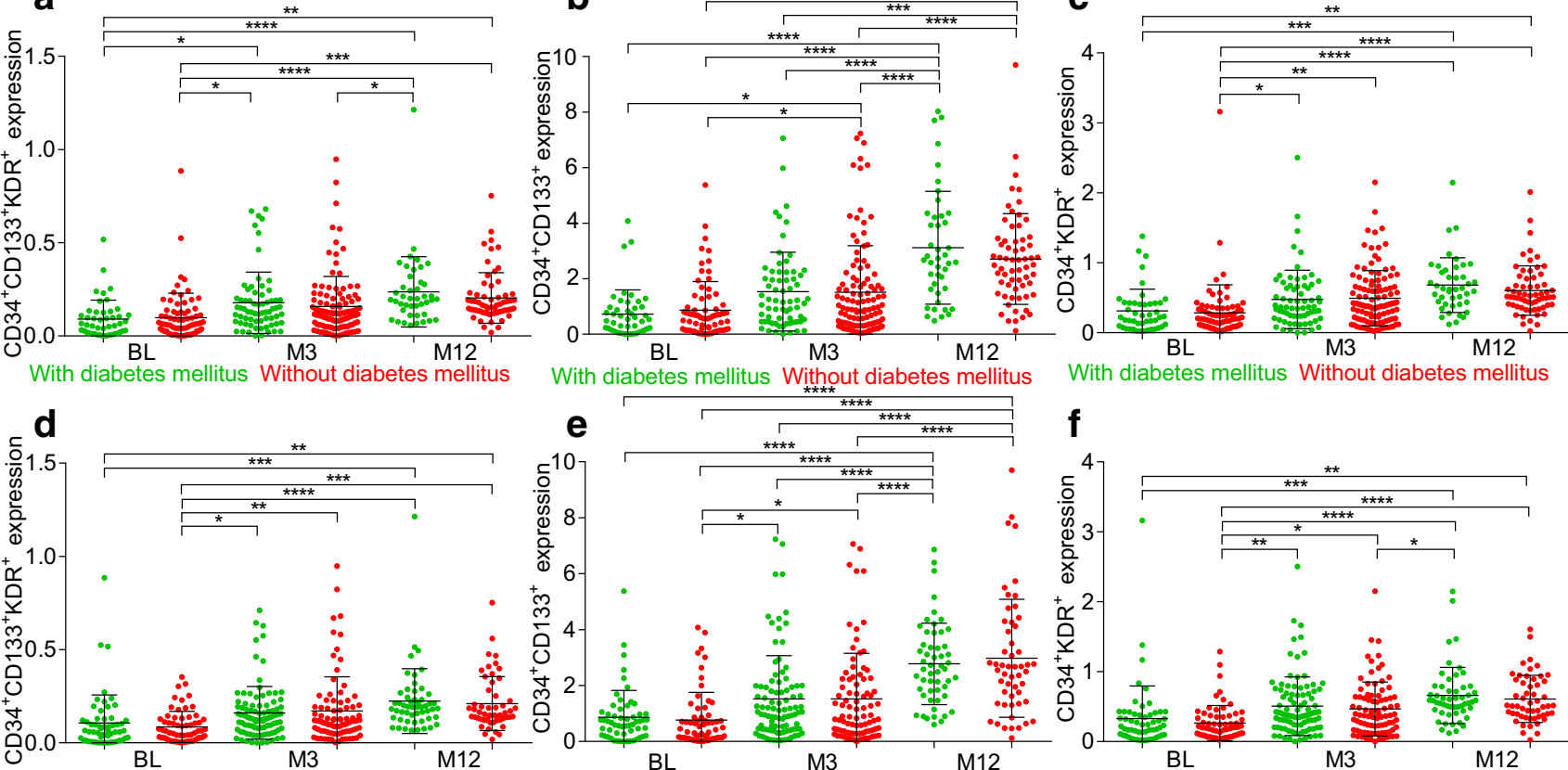

With diabetes mellitus Without diabetes mellitus

With overweight/obesity Without overweight/obesity With overweight/obesity Without overweight/obesity With overweight/obesity Without overweight/obesity
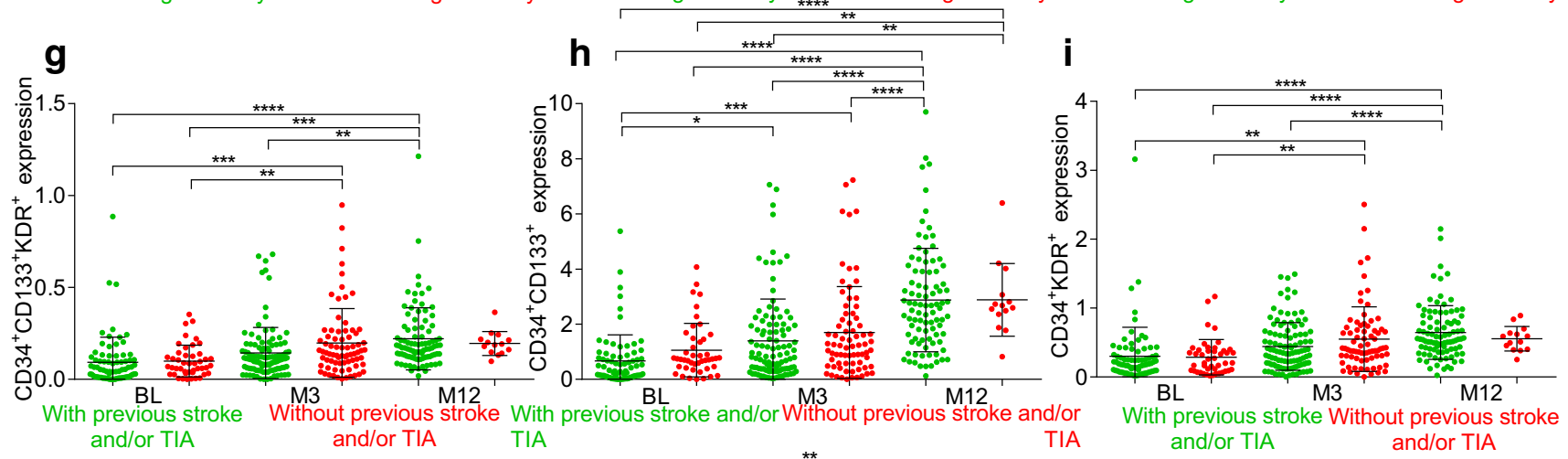
and/or TIA and/or TIA $\quad$ TIA
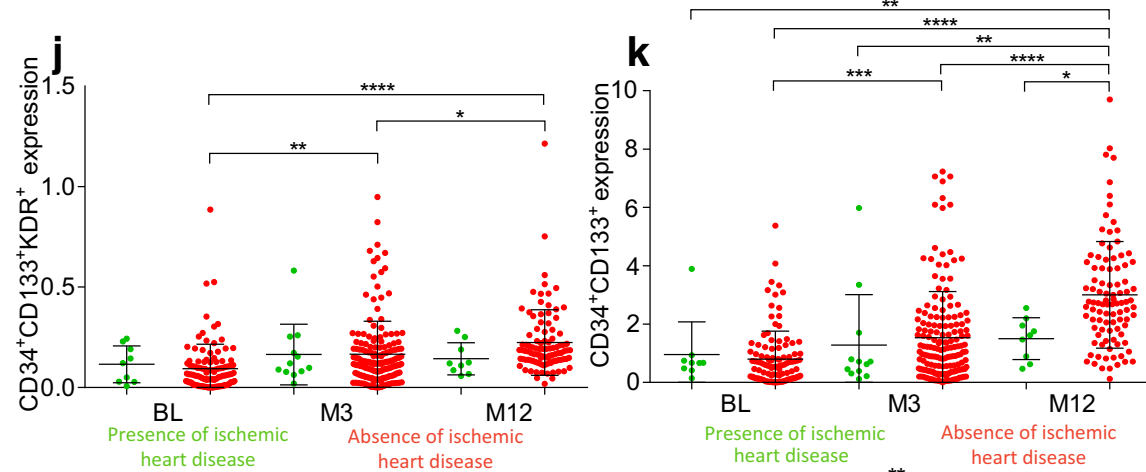
TIA
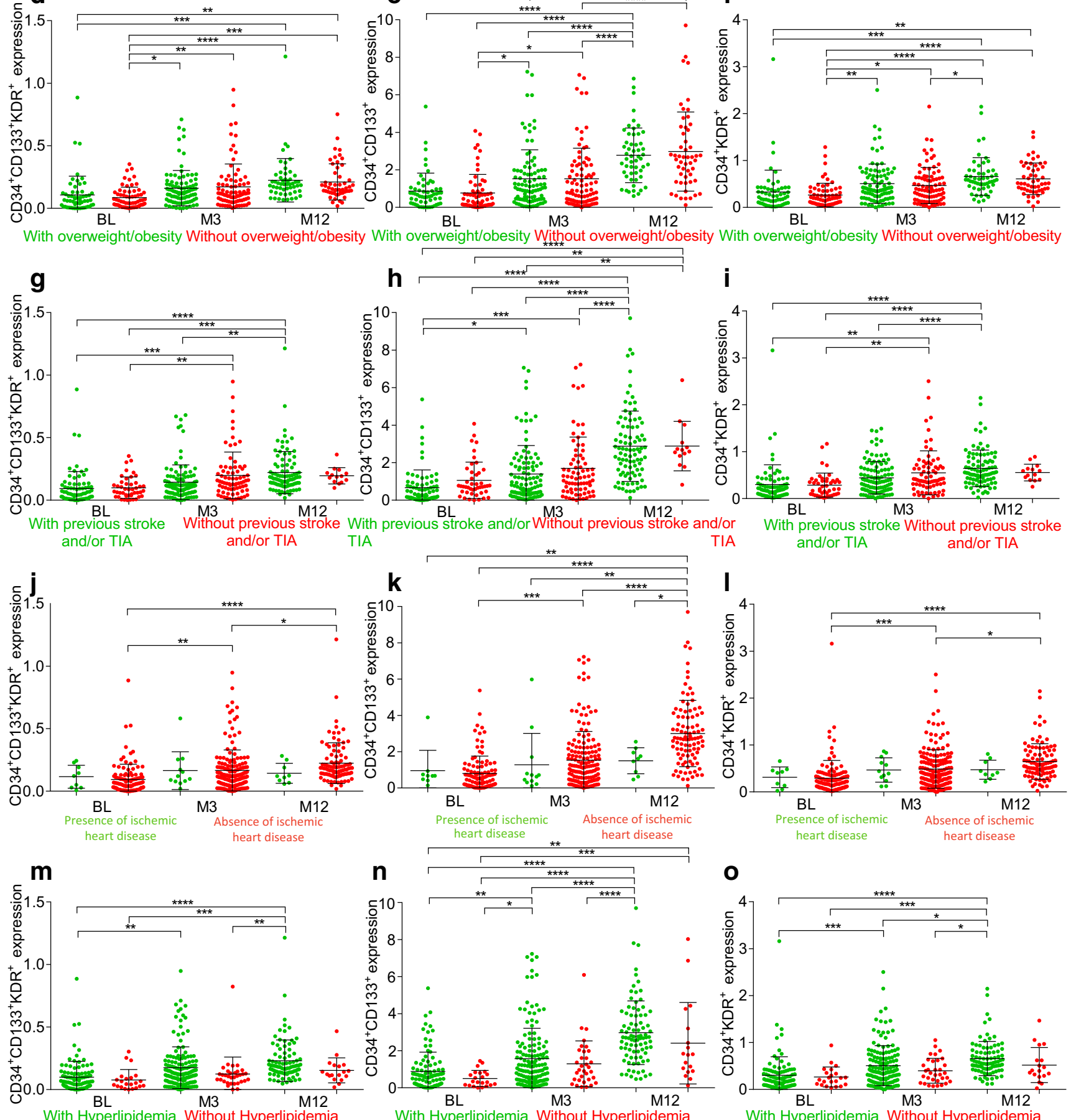
Fig. 6 Comparison of endothelial progenitor cell marker expression. Comparison of $\mathrm{CD} 34^{+} \mathrm{CD} 133^{+} \mathrm{KDR}^{+}$population, early EPCs $\left(\mathrm{CD} 34^{+} \mathrm{CD} 133^{+}\right)$and late EPCs $\left(\mathrm{CD} 34^{+} \mathrm{KDR}^{+}\right)$subpopulations between baseline (BL), month 3 time point (M3) and month 12 time point (M12) in stroke patients for following risk factors: a-c diabetes mellitus, $\mathbf{d}-\mathbf{f}$ overweight $(25<\mathrm{BMI}<30)$ and obesity $(30<\mathrm{BMI})$, (G-I) previous stroke and/or TIA, (J-L) previous ischemic heart disease and (M-O) hyperlipidemia. Green color represents the presence of risk factor. Red color represents the absence of the risk factor. The circle, triangle and square represent the three evaluation time points - BL, M3 and M12. Data represent mean $\pm \mathrm{SD}, * p \leq 0.05, * * p \leq 0.01, * * * p \leq 0.001, * * * * p \leq$ 0.0001

BMI) (Fig. 6d-f), previous stroke and/or TIA (Fig. 6g-i), previous ischemic heart disease (Fig. 6j-1), hyperlipidemia (Fig. $6 \mathrm{~m}-\mathrm{o}$ ), current or recent smoking within 6 months (Supplementary Fig. 8A-C), hypertension (Supplementary Fig. 8D-F), and atrial fibrillation (Supplementary Fig. 8G-I) on the amount of $\mathrm{CD} 34^{+} \mathrm{CD} 133^{+} \mathrm{KDR}^{+}$cell population, early EPCs $\left(\mathrm{CD} 34^{+} \mathrm{CD} 133^{+}\right)$, and late EPCs $\left(\mathrm{CD}^{2} 4^{+} \mathrm{KDR}^{+}\right)$subpopulations. PCA analyses showed a correlation between ischemic heart disease with M12 EPC, while the early EPCs $\left(\mathrm{CD} 34^{+} \mathrm{CD} 133^{+}\right)$population in the group without ischemic heart disease was significantly higher than the group with ischemic heart disease at M12 (Supplementary Fig. 7G and Fig. 6K). However, for other correlations observed from PCA such as: the correlation of BMI with EPC populations at BL (Supplementary Fig. 7B), the negative correlation of previous stroke with EPC populations at BL (Supplementary Fig. 7C), and the correlation of diabetes mellitus with M12 EPC, no significant differences were observed in the EPC subpopulations measured by flow cytometry between the presence and absence of those risk factors.

Although both ischemic stroke and TIA patients were recruited in the study, TIA patients only accounted for a
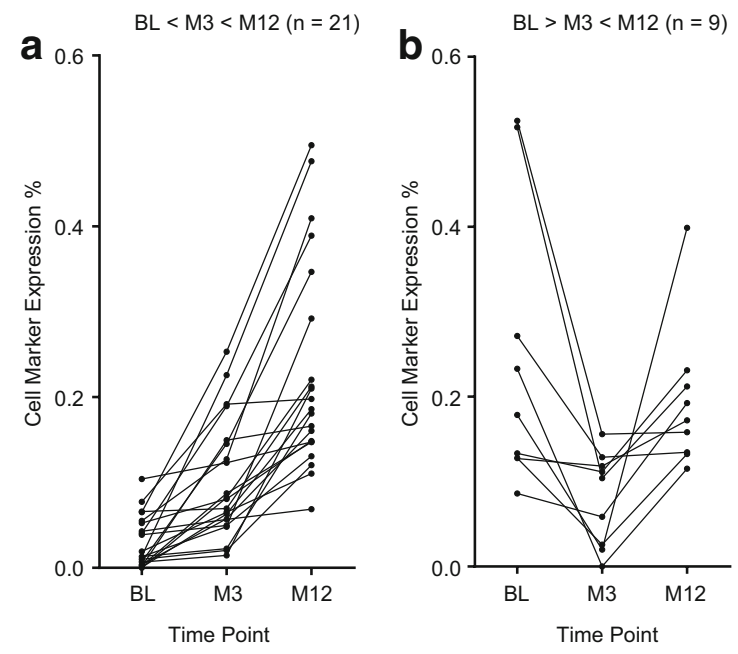

Fig. 7 Comparison of cell marker expression trends among the three time points. Comparison of amount of $\mathrm{CD} 34^{+} \mathrm{CD} 133^{+} \mathrm{KDR}^{+}$cell population among three time points: baseline (BL), month 3 time point (M3) and month 12 time point (M12) demonstrating four different value trends. a Continuous increase of values along time points $(\mathrm{BL}<\mathrm{M} 3<\mathrm{M} 12)$, b minority in the stroke group ( 24 out of 207 patients), and both patient groups were diagnosed and managed in a similar manner [34]. Moreover, the amount of EPCs, early and late EPCs did not show any statistically significant difference between ischemic stroke and TIA patients (Supplementary Fig. $8 \mathrm{~J}-\mathrm{L}$ ).

Overall, the amount of $\mathrm{CD} 34^{+} \mathrm{CD} 133^{+} \mathrm{KDR}^{+}$cell population, early EPCs $\left(\mathrm{CD} 34^{+} \mathrm{CD} 133^{+}\right)$and late EPCs $\left(\mathrm{CD} 34^{+} \mathrm{KDR}^{+}\right)$subpopulations were significantly higher in the M12 evaluation time points than BL and M3 time points, regardless of the presence (positive for risk factor) or absence (negative for risk factor) of screened vascular risk factors. Furthermore, neither the presence or absence of risk factors showed a significant influence on the amount of $\mathrm{CD} 34^{+} \mathrm{CD} 133^{+} \mathrm{KDR}^{+}$cell population, early EPCs and late EPCs subpopulations.

\section{Time Points Evaluation in Stroke Patients}

The amount of EPCs at three time points BL, M3 and M12 were quantified. Due to the variance in attendance by subjects for different time point of sample collection, only 48 patients $(n=48)$ were collected at all three time points. Four trends were observed when the amount of $\mathrm{CD} 34^{+} \mathrm{CD} 133^{+} \mathrm{KDR}^{+}$cell population of stroke patients attending all three time-points evaluation $(n=48)$ were compared (Fig. 7 , Supplementary Fig. 9):

1 Continuous increase of $\mathrm{CD} 34^{+} \mathrm{CD} 133^{+} \mathrm{KDR}^{+}$cell population (Trend 1, $n=21$, Fig. 7a) between time points $(\mathrm{BL}<$ $\mathrm{M} 3<\mathrm{M} 12$ ).

2 Decrease of $\mathrm{CD} 34^{+} \mathrm{CD} 133^{+} \mathrm{KDR}^{+}$cell population (Trend 2, $n=9$, Fig. $7 \mathrm{~b}$ ) at M3 time point and increase at M12 time point $(\mathrm{BL}>\mathrm{M} 3<\mathrm{M} 12)$.
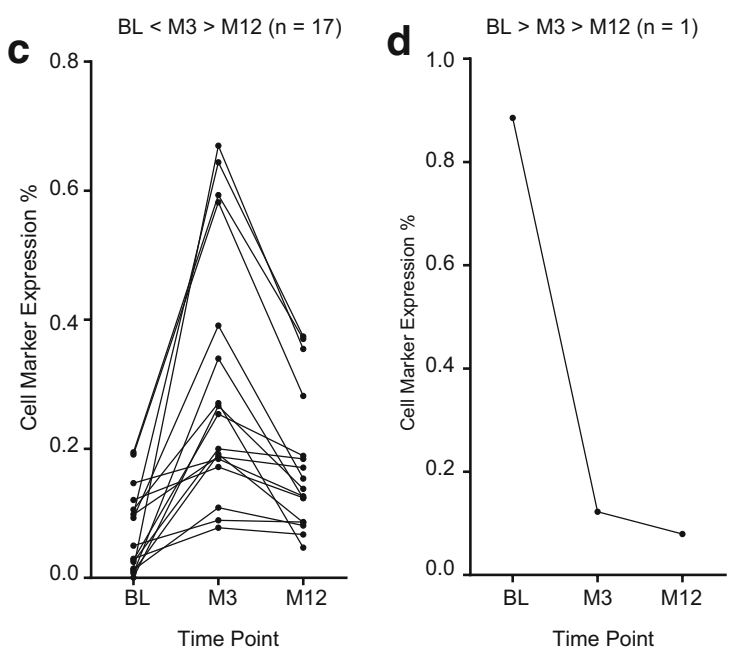

decrease of values at M3 time point and increase at M12 time point (BL $>$ M3 $<$ M12), $\mathbf{c}$ increase of values M3 time point and decrease at M12 time point $(\mathrm{BL}<\mathrm{M} 3>\mathrm{M} 12)$ and $\mathbf{d}$ continuous decrease of values along time points $(\mathrm{BL}>\mathrm{M} 3>\mathrm{M} 12)$ 
3 Increase of $\mathrm{CD} 34^{+} \mathrm{CD} 133^{+} \mathrm{KDR}^{+}$cell population (Trend $3, n=17$, Fig. $7 \mathrm{c}$ ) at M3 time point and decrease at M12 time point $(\mathrm{BL}<\mathrm{M} 3>\mathrm{M} 12)$.

4 Continuous decrease of $\mathrm{CD} 34^{+} \mathrm{CD} 133^{+} \mathrm{KDR}^{+}$cell population (Trend 4, $n=1$, Fig. 7d), early EPCs and late EPCs subpopulations between time points $(\mathrm{BL}>\mathrm{M} 3>\mathrm{M} 12)$.

Trend $1(n=21)$ correlated with male sex $(21 / 21)$, the absence of atrial fibrillation (21/21) and the absence of ischemic heart disease $(21 / 21)$. Trend $2(n=9)$ correlated with the absence of atrial fibrillation $(8 / 9$, the absence of ischemic heart disease (9/9) and the presence of a previous stroke and/or TIA (9/9). Trend $3(n=17)$ correlated with the absence of atrial fibrillation (16/17), the presence of a stroke and/or TIA (17/17) and the presence of hyperlipidemia (16/17). No observation could be made in the trend 4 group since it consists of only one subject.

\section{The HUVEC-EPC Co-Culture in Matrigel In Vitro Evaluation}

To evaluate functionality of EPCs, a Matrigel tubular formation assay in vitro with human umbilical vascular endothelial cells (HUVECs) and late EPCs represented by the $\mathrm{CD} 34^{+} \mathrm{KDR}^{+}$cell subpopulation was performed. The $\mathrm{CD} 34^{+} \mathrm{KDR}^{+}$cell subpopulation was isolated from the mononuclear fraction of peripheral blood from healthy donors and stroke patients from paired baseline (BL) and month 3 (M3) evaluation time points (Supplementary Table 1). The tube-like structures were evaluated for several parameters that indicate vasculogenic properties. The HUVECs and HUVEC-late EPCs co-culture demonstrated variety of tube-like structures when stained with calcein AM (Fig. 8a-b). The tube-like structures were quantified via Metamorph software for various parameters and the related paired tubular formation assay and EPC expression data from the stroke patients were analyzed (Fig. 8c-f).

Overall, HUVECs cultured in the EGM-2MV, which was the positive control of the tube formation assay, demonstrated significantly higher performance of tube-like structure formation when compared with all other groups. The other positive controls, the HUVECs that were cultured in EBM-FV (basal endothelial medium enriched with $3 \%$ FBS and $10 \mathrm{ng} / \mathrm{ml}$ VEGF), or only in EBM-F (basal endothelial medium enriched with $3 \%$ FBS) also demonstrated a capability of tube-like structures and tube network formation.

The HUVECs $-\mathrm{CD} 34^{+} \mathrm{KDR}^{+}$co-culture showed following interesting trends. The $\mathrm{CD} 34^{+} \mathrm{KDR}^{+}$cells from healthy donor below and above or equal to 45 years of age groups in the co-culture with HUVECs demonstrated tube-like structure formation comparable with HUVECs in EBM-FV and EBM$F$ media. Furthermore, the tubular formation performance in Matrigel of healthy donor $\mathrm{CD} 34^{+} \mathrm{KDR}^{+}$cells of both age groups was significantly higher than the tubular formation performance of stroke patient $\mathrm{CD} 34^{+} \mathrm{KDR}^{+}$cells. It was also observed that healthy donor above or equal to 45 years of age group demonstrated a larger variation of the tube-like structure formation when compared to healthy donor below 45 years of age $\mathrm{CD} 34^{+} \mathrm{KDR}^{+}$cells group.

When examining the EPCs from stroke patients, the HUVECs $-\mathrm{CD} 34^{+} \mathrm{KDR}^{+}$co-culture of stroke patients of BL and $\mathrm{M} 3$ evaluation time points demonstrated the lowest tubelike structure formation capability when compared to all other quantified groups. Paired data of EPC from the same set of stroke patients $(n=8)$ with EPC analysis at different time points (BL and M3) were also compared. The tubeformation analysis of the paired data shows mixed trends though the late EPC subpopulation expressions were significantly increased in those patients from BL to M3 (Fig. 8g).

The ten stroke patients whose samples analyzed for tubular formation assay are associated with hyperlipidemia (7/10), hypertension (4/10), diabetes mellitus (1/10) and atrial fibrillation (1/10). All ten patients have history of taking statins (10/ 10). Interestingly, the hyperlipidemia was weakly negatively correlated with the tubular formation parameters at M3 timepoint, BMI was weakly correlated with tubular formation parameters at M3 in principal component analysis (Supplementary Fig. 10).

\section{Discussion}

The discovery of EPCs and their capability to participate in the reparation process of vascular damage has led to efforts to characterize EPCs and their functional properties [12-14]. It has been postulated that EPCs have unique properties with respect to their migration, proliferation and differentiation [35], and that the process of aging may lead to deterioration of progenitor cell functions, termed progenitor exhaustion [36, 37]. Moreover, it has been recently shown that viral factors such as the severe acute respiratory syndrome coronavirus 2 (SARS-CoV-2) could pose a crucial threat in causing EDF and subsequently in cardiovascular diseases (CVDs) [38]. Therefore, it comes without a surprise that a substantial effort was put into the assessment of EPCs as a potential biomarker and therapeutic agent. In this study, the influence of age, sex, ethnicity, morbidity and various CVD risk factors on the amount of circulating EPCs was investigated. Additionally, the $\mathrm{CD} 34^{+} \mathrm{CD} 133^{+} \mathrm{KDR}^{+}$cell population was analyzed for its developmental stage subpopulations $-\mathrm{CD} 34^{+} \mathrm{CD} 133^{+}$cells (termed as early EPCs) and $\mathrm{CD} 34^{+} \mathrm{KDR}^{+}$cells (termed as late EPCs), which have been demonstrated to exhibit specific properties varying in their functionality [15-17]. The results showed that there is an increase of EPCs in individuals older than 45 years regardless of health status. Stroke patients showed significantly higher amounts of EPCs at 12 months 
a Complete growth medium

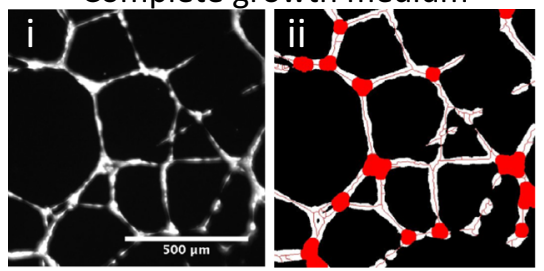

b

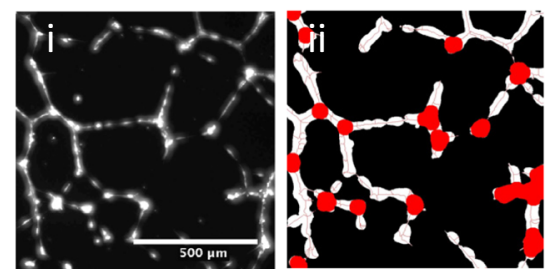

C
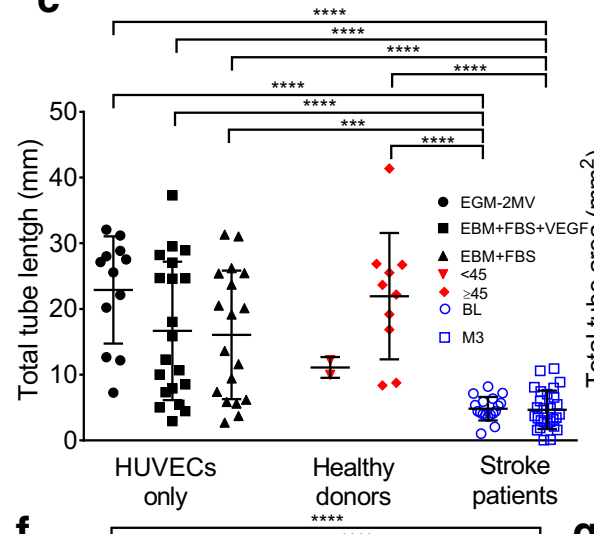

d

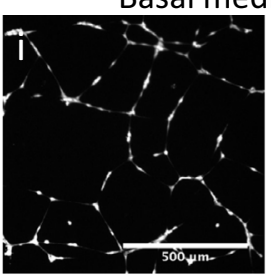

HUVEC only

HUVEC-EPC co-culture

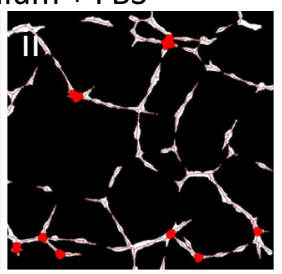

$\mathrm{BL}$

Stroke patients
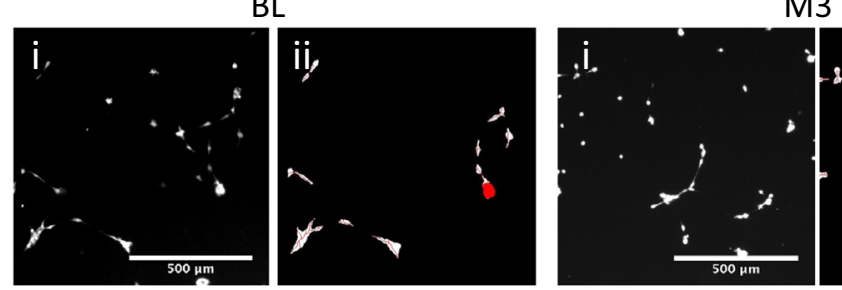

M3

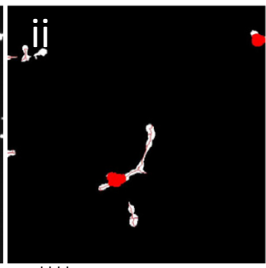

e
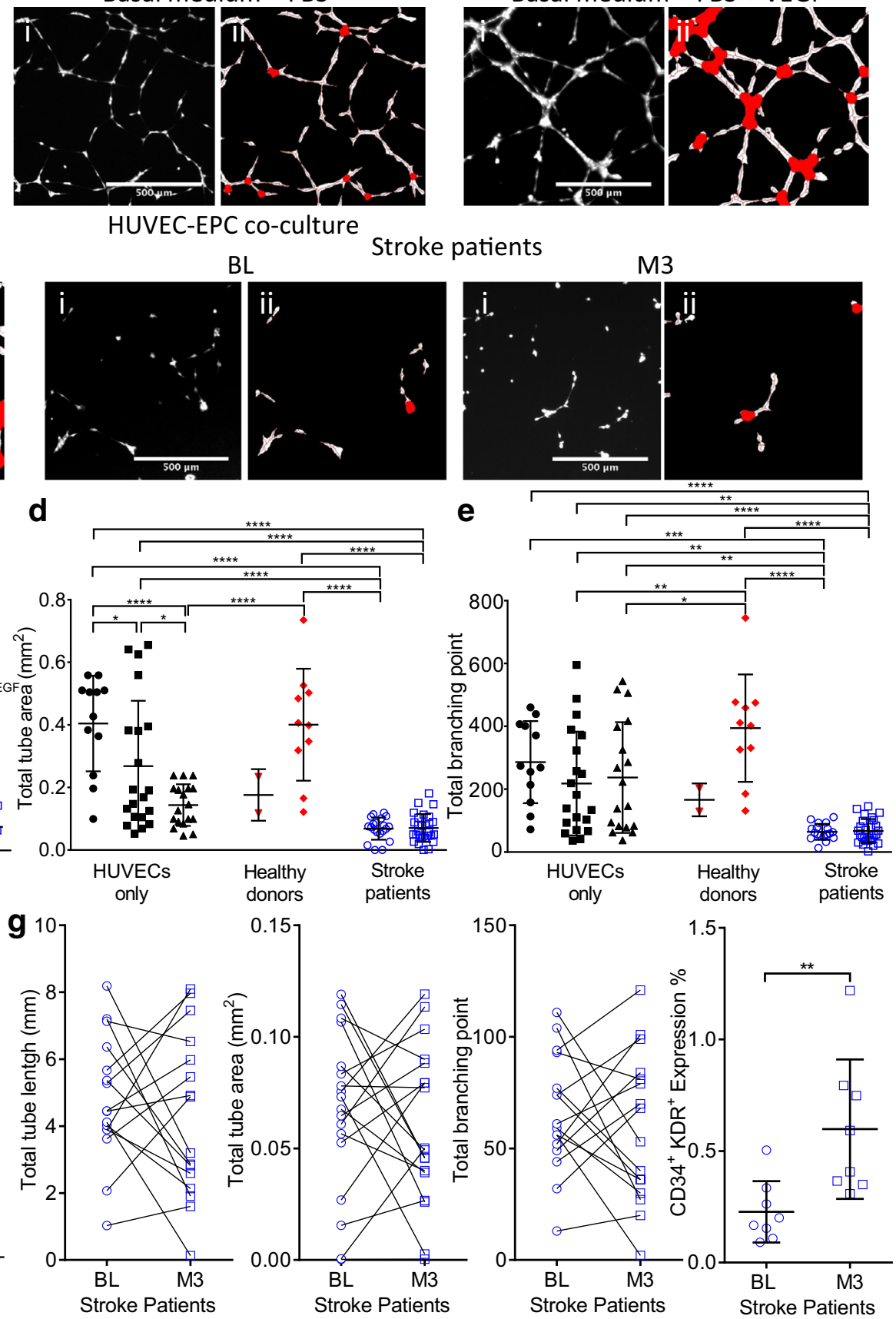

Fig. 8 Comparison of tube-like structures formed by human umbilical vein endothelial cells (HUVECs) and co-culture of HUVECs-late EPCs in a Matrigel assay. Comparison of tube-like structures of calcein AM stained images (i) and Metamorph processed images (ii) for (a) HUVECs only, cultured in EGM-2MV, EBM-FV and EBM-F; b HUVECs and the late EPCs $\left(\mathrm{CD} 34^{+} \mathrm{KDR}^{+}\right)$from healthy donors cultured in EBM-F, HUVECs and the late EPCs from stroke patients at BL and M3 evaluation time points. Bar $=500 \mu \mathrm{m}$, magnification $(10 \mathrm{X})$. Quantification of tubular formation in HUVECs (HUVECs only) cultured in EGM-2MV (circle), EBM-FV (square) and EBM-F (triangle); co-culture of HUVECs

and late EPCs $\left(\mathrm{CD} 34^{+} \mathrm{KDR}^{+}\right)$from healthy donors $<45$ and $\geq 45$ years of age cultured in EBM-F and co-culture of HUVECs and CD34 ${ }^{+} \mathrm{KDR}^{+}$ cell population from stroke patients at $\mathrm{BL}$ and $\mathrm{M} 3$ evaluation time points cultured in EBM-F. $\mathbf{c}$ total tube length in $\mathrm{mm}, \mathbf{d}$ total tube area in $\mathrm{mm}^{2}, \mathbf{e}$ total count of branching points and $\mathbf{f}$ total count of nodes. Among the tubular formation data, 8 pairs of samples were obtained from respective stroke patients at both time points BL and M3. g Comparison of total tube length, total tube area and total branching point trends between BL and $\mathrm{M} 3$ and, $\mathrm{CD} 34^{+} \mathrm{KDR}^{+}$expression of respective stroke patients. Data represent mean $\pm \mathrm{SD}, * p \leq 0.05, * * p \leq 0.01, * * * p \leq 0.001, * * * * p \leq 0.0001$ 
post stroke and/or TIA. Most importantly, the capability of EPCs from healthy donors and stroke patients to influence the HUVEC tube-formation in Matrigel in vitro were different mainly dependent on the donor's health status. Although higher level of circulating EPCs were observed in stroke patients, the isolated $\mathrm{CD} 34^{+} \mathrm{KDR}^{+} \mathrm{EPC}$ subpopulation, which are responsible for vasculogenesis and angiogenesis, showed an impaired tubular formation capability when compared to healthy donors. Such findings suggested a crucial inability of EPCs to participate in successful functional recovery in stroke patients.

The influence of aging on the quality and quantity of EPCs is still controversial. In a group of individuals aged 4380 years, age-dependent depression of circulating EPCs, which could not be explained by differences in atherosclerotic risk factors or cardiac function, was demonstrated [39]. However, other studies suggested that age does not influence the decline of EPCs [37, 40]. For instance, Heiss et al. found that the amount of circulating $\mathrm{CD} 34^{+} \mathrm{KDR}^{+}$and $\mathrm{CD}_{13} 3^{+} \mathrm{KDR}^{+}$cell subpopulations in peripheral blood did not differ between old ( $61 \pm 2$ years) and young ( $25 \pm 1$ years) healthy individuals. Instead, the group demonstrated that the migration and proliferation of EPCs were significantly lower in older individuals and thus concluded that age influences the quality rather than the quantity of EPCs [37]. This was supported by another study which concluded that aging leads to impairment of EPC functions and altering the migration of EPCs [41].

The quantity of EPCs in stroke patients varied at different time-point post stroke. A previous study performed by MartíFàbregas et al. showed that the EPCs, characterized as $\mathrm{CD} 34^{+} \mathrm{CD} 133^{+} \mathrm{KDR}^{+}$cell population, peaked at 1 week after stroke onset and declined in the following 12 weeks [42]. The current study observed a significant increase of EPCs at 3 months and 12 months when compared to the first evaluation performed within 7 days post stroke (baseline; BL) in stroke patients. The quantities of different EPC subpopulations $\left(\mathrm{CD} 34^{+} \mathrm{CD} 133^{+}\right.$and $\left.\mathrm{CD} 34^{+} \mathrm{KDR}^{+}\right)$, which are defined by the differences in developmental stage and functionality, were significantly increased in the third month (M3) post stroke and peaked at 12 month (M12). The EPC level at M12 was also significantly higher than EPCs in healthy individuals. These findings suggested that a vascular injury such as a cerebral ischemia elevates EPC recruitment to peripheral blood and result in significantly increased EPC amounts in stroke patients.

Similar to the age-related influence on EPCs, sex-related studies seem to contradict each other. A sex-related difference in the amount of circulating EPCs was found in a study of women and men aged 40 to 58 years [43]. Another study, however, failed to find any age-related difference in the peripheral blood EPCs of men and women aged 45 to 65 years [44]. Our present evaluation of healthy individuals and stroke patients aged 20-87 years did not demonstrate any sex-related difference in the amount of circulating EPCs. Although the PCA screening of our data demonstrated a slightly positive correlation with M12 EPC subsets in males, and a slightly negative correlation in females, the correlations are not statistically insignificant $(p>0.05)$. A further investigation with a larger sample size will be necessary before any final conclusions on the correlation with sex could be drawn. In addition, the present observations appear to be the first to indicate that quantity or quality of EPCs are not influenced by ethnicity. As such, there are no previous data for comparison.

Moreover, EPC dysfunction may be affected by a number of cardiovascular risk factors and other diseases such as pulmonary diseases [45], including smoking and obesity. According to PCA screening analysis for risk factors, diabetes mellitus and previous stroke or TIA were the highest contributing variables for the principal component $1, \mathrm{BMI}$ and smoking (current or within 6 months before study) were the highest for principal component 2, and atrial fibrillation was the lowest contributor for both components. From the PCA screening analysis, several risk factors were observed to have potential correlations with the EPC levels. For instance, BMI was correlated with EPC populations at BL (Supplementary Fig. 3B), diabetes mellitus was correlated with M12 EPC, while ischemic heart diseases were negatively correlated with M12 EPC. Among all the potential correlations, our data show that the early EPC $\left(\mathrm{CD} 34^{+} \mathrm{CD} 133^{+}\right)$population in the group without ischemic heart disease was significantly higher $(p<0.05)$ than the group with ischemic heart disease at M12 (Fig. 6k). Interestingly, but not surprisingly, when comparing the correlation of risk factors with each other utilizing PCA (Supplementary Fig. 6B), BMI was coupled with hyperlipidemia and diabetes mellitus with hypertension, while previous stroke and/or TIA and ischemic heart disease were positively correlated to each other.

Several studies have also explored the influence of CVD risk factors on EPCs. For example, it was demonstrated that diabetes mellitus [46], smoking [45], hypertension [47] and atherosclerosis [48] showed no effect on the quantity of EPCs. However, samples from patients treated with statins showed a correlation between quantity and/or functionality of EPCs with hyperlipidemia, hypertension, diabetes mellitus and atrial fibrillation [5, 49]. The present results, which also demonstrated a lack of significant difference in the quantity of EPCs in relation to the presence or absence of screened vascular risk factors, are consistent with the previous findings. However, it has to be noted that the presence of a single risk factor is rare, and hence a more complex evaluation of multiple risk factors and their combinations in an individual will be necessary. The complexity of multiple risk factors, the influences and interactions among the multiple risk factors, combining with the small group of subjects recruited in the current study were the major limitations to perform an evaluation of multiple risk 
factors. Therefore, multiple factor analysis of EPC quantities, EPC functional performance with CVD risk factors was not pursued.

To evaluate the functionality of the EPC subpopulation (late EPCs - CD $34^{+} \mathrm{KDR}^{+}$cell subpopulation) responsible for vasculogenesis a standard an in vitro Matrigel tubular formation assay was performed. The Matrigel assay has been shown as an efficient indicator for assessment of EPCs functionality [50]. Moreover, the Matrigel assay parameters were shown to be indicators for various vasculogenic processes, such as the potential for vasculogenesis (total count of tubes and loops), responsiveness to angiogenic factors (number of branch points) and cytokine production (tube length, tube thickness) [51]. Previous studies have shown variability in EPC functionality and their capability to form $[52,53]$ or not to form tubes and capillaries and therefore require supporting cells [55]. Our experimental design required a fast identification and isolation of circulating EPCs. Therefore, in this study, we referred the subpopulation of EPCs exhibiting surface markers CD34+ and KDR+ as "late EPCs" according to the literature $[12,13]$. The $\mathrm{CD} 34+/ \mathrm{KDR}+$ population could be easily identified and isolated by a flow cytometry procedure. On the other hand, outgrowth EPCs are identified as mononuclear cells cultured in a flask exhibiting cobblestonelike morphology and multiple surface markers; several studies suggested the late outgrowth EPCs are more proliferative than early-outgrowth EPCs [52-54]. Moreover, it was demonstrated that late out-growth EPCs are better at forming capillarylike tubes [52, 53]. Late EPCs as termed previously by characterization based mainly on surface markers [12-17] have shown lower capillary-like tubes forming capability in previous studies [55]. In our pilot study, we examined the functionality of EPCs, early and late EPCs, all of which demonstrated low proliferative capability and a poor performance in capillary-like tube formation when cultured by themselves. It is important to note that majority of the studies vary in the EPC definition, isolation, characterization and the amount of cells used for Matrigel tubular formation assay [52, 53, 55]. We hypothesized that the functionality of EPCs will be influenced by the age and/or health status of the subjects and thus with the results observed in our pilot study, we performed a co-culture of HUVECs with late EPCs characterized by flow cytometry as $\mathrm{CD} 34+\mathrm{KDR}+$ cell population. The results of the Matrigel assay demonstrated the significantly decreased ability of stroke patients' EPCs to form tube-like structures. Our findings are supported by another study demonstrating a similar impairment of EPCs from patients with chronic renal failure and their inability to form tube-like structures in co-culture with HUVECs in a Matrigel assay [25]. The current study demonstrated an active participation of EPCs in tube-like structure formations in the co-culture with HUVECs, and the current findings are in agreement with previous studies that observed an active involvement of EPCs in vasculogenesis
[15-17, 25]. The full extent of tube formation mechanism, potential paracrine effect and the overall decreased functionality of stroke patients EPCs were not further investigated and thus represent the limitation of the functional assay in this study. Nevertheless, it is speculated that the decreased functionality of EPCs could be due to mechanisms similar to those previously proposed by other studies $[41,45,56]$; the potential cause of the decreased functionality are: 1) alternation in EPC DNA, 2) alternation in EPC migration capability, 3) alternation in EPC recruitment to damaged ischemic tissues and/ or 4) decreased or absent paracrine and autocrine function. An important aspect of EPC functionality is their paracrine action. Stem cells have been shown to be capable of releasing of soluble biofactors (SBF) that have immunomodulatory, antiinflammatory, tissue protective and regenerative effects [57], and the paracrine function of EPCs plays a crucial role in the post-stroke phase $[58,59]$. The decreased capability, or even inability, of secreting SBF would dramatically affect EPC performance and thus resulted in decreased or absent angiogenesis and vascular repair. The vascular injury in stroke and associated diseases such as hyperlipidemia could elevate EPC recruitment to peripheral blood, resulting in increased EPC quantities; however, the vascular dysfunction presented in stroke patients could also impair or reduce vasculogenic or angiogenic capacity of the EPCs as demonstrated by the current study. In addition, all patients whose samples were included in the Matrigel tubular assay had a history of statins therapy, which is a parameter that was previously discussed as a factor augmenting the quantities and/or functionality of EPCs [49]. The characteristics of EPCs in stroke patients have the potential to predict the outcome of stroke and/or other vascular events as it was demonstrated by studies focusing on EPC subpopulations and their correlation with vascular diseases [60-63]. A study with a focus on circulating $\mathrm{CD} 133^{+} \mathrm{CD} 34^{+}$EPCs demonstrated correlations between the quantity of EPCs and outcome of acute ischemic stroke [62]. Furthermore, several other studies showed a potential for EPCs to be of value as biomarker for the prediction of stroke outcome $[60,61,64]$. EPCs also showed potentials in various applications, including cell therapy $[1,65]$ or even as a autologous EPC transplantation therapy in patients with acute ischemic stroke [66]. The rare occurrence of $\mathrm{CD} 34^{+} \mathrm{CD} 133^{+} \mathrm{KDR}^{+}$EPCs in peripheral blood $(0.01-$ $0.001 \%$ ) [12-14] and the age-related depression of EPC functionality $[37,40,41]$ highlights the importance of other cell sources that would mimic the vasculogenic properties of EPCs. Consistent with the hypothesis of the current study, we found that the quantity of circulating EPCs in peripheral blood varied with age and varied between healthy donors and stroke patients. Moreover, the functionality of EPCs was showed to be significantly influenced by health status, and decreased functionality could lead to a crucial impairment in vascular regeneration. 


\section{Conclusions}

This study reported a systematic qualitative and quantitative characterization of EPCs from stroke patients at three different evaluation time-points, and healthy donors of different ages. The quantity of EPCs from stroke patients at 3 months and 12 months after stroke was significantly higher than the quantity of EPCs recorded within 7 days post-stroke. The EPC level peaked at 12 months post-stroke, which was significantly higher than all other groups including the healthy donors. The early and late EPC subpopulations were significantly increased at M3. The increase in amount of EPCs suggested that the recovery response of ischemic stroke triggers the increase of EPCs in the peripheral blood. However, the mechanisms of the increase in EPC level are unclear and yet to be investigated.

The functionality of EPCs, as measured by their tubeformation capability in in vitro Matrigel assay, showed that EPCs from stroke patients formed less tubes than EPCs from healthy donors. The results indicate that the functionality of EPCs in stroke patients could be impaired by the ischemic stroke or related vascular dysfunctions.

This study demonstrated the influence of stroke on the fluctuations of the quantity of EPCs over time and the deteriorated functionality of EPCs post-stroke. However, further verification will be necessary in studies with larger population size.

Acknowledgements The authors would like to thank the NUS Tissue Repository for their assistance in cell isolation and cryo-storage, Dr. Mie Yamamoto for her technical help and discussion in setting up the EPC isolation, Ms. Dawn Neo, Ms. Jia Yi Yao and Mr. Thanadet Chuangsuwanich for their assistance in FACS sample handling and tube-formation assay, assistance from Ms. Geelyn Ng and Ms. Mary $\mathrm{Ng}$ for the healthy donor blood collection, Mrs. Ting for administrative support.

Author Contributions MK, DW, CMT did the EPC isolation, MK and DW did the in vitro studies. MK, AMZ, EY did the data analysis and writing. RS, BC, EY and PW designed the clinical study; MK, DW and EY designed the in vitro studies.

Funding This work was supported by the National Research Foundation, Prime Minister's Office, Singapore under its Competitive Research Program (NRF-CRP03-2008 - 01) and its Research Centre of Excellence programme administered by the Mechanobiology Institute, Singapore, and partially supported by National Institute of Health (NIH R01 HL130274-01A1) and the University of Waterloo Startup Fund. MK was supported by scholarship from the Mechanobiology Institute, Singapore funded by National Research Foundation Singapore and Ministry of Education Singapore. AMZ is supported by National Institute of Health (NIH R01 HL130274-01A1).

Data Availability All data generated or analyzed during this study are included in the published article.

\section{Compliance with Ethical Standards}

Conflict of Interest The authors declare that they have no conflict of interest.
Ethics Approval and Consent to Participate The study protocol was reviewed and approved by the Institutional Review Board, National Healthcare Group, Singapore. The study was conducted in accordance with the guidelines on good clinical practice and with the ethical standards for human experimentation established by the Declaration of Helsinki. All subjects gave written consent before being included in the study.

List of Abbreviations $B L$, Baseline; $B M I$, Body mass index; $B S A$, Bovine serum albumin; CVDs, Cardiovascular diseases; DMSO, Dimethyl sulfoxide; $E B M$, Endothelial basal medium; $E G M$, Endothelial growth medium; $E C s$, Endothelial cells; $E D F$, Endothelial dysfunction; EDTA, Ethylendiaminetetraacetic acid; EPCS, Endothelial progenitor cells; FACS, Fluorescence activated cell sorting; FBS, Fetal bovine serum; $F M O$, Fluorescence minus one; $h E G F$, human epidermal growth factor; $h F G F-B$, human fibroblastic growth factor $\mathrm{B} ; H S$, Hemorrhagic stroke; HUVECs, Human umbilical vein endothelial cells; $I H D$, Ischemic heart disease ; $I S$ :, Ischemic stroke; $M 3$, 3 months; $M 12$;, 12 months; NO, Nitric oxide; $P C A$, Principal component analysis; $P F A$, Paraformaldehyde; $R^{3}-I G F-1$, Insulin-like growth factor $1 ; R B C$, Red blood cell; RPMI, Rosswell Park Memorial Institute Medium; SARS$\mathrm{CoV}$-2, Severe acute respiratory syndrome coronavirus 2; $S B F$, Soluble biofactors; TIA, Transient ischemic attack; $V E G F$, Vascular endothelial growth factor; Early EPCs, $\mathrm{CD} 34^{+} \mathrm{CD} 133^{+}$population; Late EPCs, $\mathrm{CD} 34^{+} \mathrm{KDR}^{+}$population

\section{References}

1. Li, Y. F., Ren, L. N., Guo, G., \& Cannella, L. A. (2015). Endothelial progenitor cells in ischemic stroke: An exploration from hypothesis to therapy. Journal of hematology \&Oncology, 8,33 .

2. Vanhoutte PM (1997).Endothelial dysfunction and atherosclerosis. In: European Heart Journal. Vol. 18: The Oxford University press; 1997: 19-29.

3. Ribeiro FF, Alves AJA, Teixeira MM, Ribeiro VV, Duarte JAJ, Oliveira JJ (2009).Endothelial function and atherosclerosis: circulatory markers with clinical usefulness. In: Rev Port Cardiol. vol. $28:: 1121-1151$.

4. Widlansky ME, Gokce N, Keaney J, John F, Vita JA (2003). The clinical implications of endothelial dysfunction $J$ Am Coll Cardiol 42; 2003: 1149-1160.

5. Su, J. B. (2015). Vascular endothelial dysfunction and pharmacological treatment. World Journal of Cardiology, 7(11), 719-741.

6. Anderson, T. J., Meredith, I. T., Yeung, A. C., Frei, B., Selwyn, A. P., \& Ganz, P. (1995). The effect of cholesterol-lowering and antioxidant therapy on endothelium-dependent coronary vasomotion. The New England Journal of Medicine, 332(8), 488-493.

7. Santos-Parker, J. R., LaRocca, T. J., \& Seals, D. R. (2014). Aerobic exercise and other healthy lifestyle factors that influence vascular aging. Advances in Physiology Education, 38(4), 296-307.

8. Hughes K, Yeo PP, Lun KC, Thai AC (1990).Cardiovascular diseases in Chinese, Malays, and Indians in Singapore. II. Differences in risk factor levels. In: J. Epidemiol. Community Health, 1990.

9. Gunarathne, A., Patel, J. V., Gammon, B., Gill, P. S., Hughes, E. A., \& Lip, G. Y. H. (2009). Ischemic stroke in south Asians: A review of the epidemiology, pathophysiology, and ethnicity-related clinical features. Stroke, 40, e415-e423.

10. Kim BJ, Kim JS (2014). Ischemic stroke subtype classification: an asian viewpoint $J$ Stroke 16; 2014: 8-10.

11. Bang, O. Y. (2016). Considerations when subtyping ischemic stroke in Asian patients. J Clin Neurol, 12, 129-128.

12. Asahara, T. (1997). Isolation of putative progenitor endothelial cells for angiogenesis. Science, 275, 964-966. 
13. Khan, S. S., Solomon, M. A., \& JP, M. C. (2005). Detection of circulating endothelial cells and endothelial progenitor cells by flow cytometry. Cytometry, 64B, 1-8.

14. Calzi SL, Neu MB, Shaw LC, Kielczewski JL, Moldovan NI, Grant MB (2010).EPCs and pathological angiogenesis: When good cells go bad. In: Microvascular Research. vol. 79: Elsevier Inc.; 2010: 207-216.

15. Cheng C-C, Chang S-J, Chueh Y-N, Huang T-S, Huang P-H, Cheng S-M, Tsai T-N, Chen J-W, Wang H-W (2013).Distinct angiogenesis roles and surface markers of early and late endothelial progenitor cells revealed by functional group analyses. In: $B M C$ Genomics. vol. 14: BMC Genomics; 2013: 1-1.

16. Hur J, Yoon CH, Kim HS, Choi JH, Kang HJ, Hwang KK, Oh BH, Lee MM, Park YB (2004). Characterization of two types of endothelial progenitor cells and their different contributions to Neovasculogenesis. In: Arteriosclerosis, Thrombosis, and Vascular Biology. vol. 24; 2004: 288-293.

17. Tagawa S, Nakanishi C, Mori M, Yoshimuta T, Yoshida S, Shimojima M, Yokawa J, Kawashiri M-a, Yamagishi M, Hayashi K (2015).Determination of Early and Late Endothelial Progenitor Cells in Peripheral Circulation and Their Clinical Association with Coronary Artery Disease. In: International Journal of Vascular Medicine, 2015: 1-7.

18. Gehling, U. M., Ergün, S., Schuch, G., Schafhausen, P., Kilic, N., Schäfer, B., Hossfeld, D. K., \& Fiedler, W. (1999). In vitro differentiation of endothelial cells (EC) from AC133-positive progenitor cells. European Journal of Cancer, 35, S103-S104.

19. Peichev M, Naiyer AJ, Pereira D, Zhu Z, Lane WJ, Williams M, Oz MC, Hicklin DJ, Witte L, Moore MA et al (2000).Expression of VEGFR-2 and AC133 by circulating human CD34(+) cells identifies a population of functional endothelial precursors. In: Blood, 95: 952-958

20. Lee PSS (2014).Endothelial progenitor cells in cardiovascular diseases. In: WJSC, 6: 355-313.

21. Hristov, M., \& Weber, C. (2008). Endothelial progenitor cells: Cellular biomarkers in vascular disease. Drug Discovery Today: Disease Mechanisms, 5, e267-e271.

22. Gu, W., Sun, W., Guo, C., Yan, Y., Liu, M., Yao, X., Yang, B., \& Zheng, J. (2015). Culture and characterization of circulating endothelial progenitor cells in patients with renal cell carcinoma. The Journal of Urology, 194, 214-222.

23. Campioni D, Zauli G, Gambetti S, Campo G, Cuneo A, Ferrari R, Secchiero P (2013).In vitro characterization of circulating endothelial progenitor cells isolated from patients with acute coronary syndrome PLoS ONE. Vol. 8; e56377-e56379.

24. Hernandez SL, Gong JH, Chen L, Wu I-H, Sun JK, Keenan HA, King GL (2014).Characterization of circulating and endothelial progenitor cells in patients with extreme-duration type 1 diabetes. In: Diabetes Care. vol. 37; 2014: 2193-2201.

25. Choi JH (2004).Decreased number and impaired Angiogenic function of endothelial progenitor cells in patients with chronic renal failure. In: Arteriosclerosis, Thrombosis, and Vascular Biology. vol. 24 ; 2004: 1246-1252.

26. Fadini GP (2006).Number and function of endothelial progenitor cells as a marker of severity for diabetic vasculopathy. In: Arteriosclerosis, Thrombosis, and Vascular Biology. vol. 26; 2006: $2140-2146$

27. Zhao, W., Zhao, L., Liao, J., Luo, Y., \& He, L. (2019). Early risk assessment of circulating endothelial progenitor cells and plasma stromal cell-derived factor-1 for nondisabling ischemic cerebrovascular events. BMC Neurology, 19(1), 22.

28. Zhao, Y.-H., Yuan, B., Chen, J., Feng, D.-H., Zhao, B., Qin, C., \& Chen, Y.-F. (2012). Endothelial progenitor cells: Therapeutic perspective for ischemic stroke. CNS Neurosci Ther, 19, 67-75.

29. Burger D, Touyz RM (2012).Cellular biomarkers of endothelial health: Microparticles, endothelial progenitor cells, and circulating endothelial cells. In: Journal of the American Society of Hypertension. vol. 6: Elsevier Ltd; 2012: 85-99.

30. Fuss, I. J., Kanof, M. E., Smith, P. D., \& Zola, H. (2001). Isolation of whole mononuclear cells from peripheral blood and cord blood. In.: John Wiley \& Sons. Inc., 2001, 1-8.

31. Arnaoutova I, Kleinman HK (2010).In vitro angiogenesis: Endothelial cell tube formation on gelled basement membrane extract. In: Nat Protoc. vol. 5: Nature publishing group; 2010: 628635.

32. Smajlovic, D. (2015). Strokes in young adults: Epidemiology and prevention. Vascular Health and Risk Management, 11, 157-164.

33. Kissela, B. M., Khoury, J. C., Alwell, K., Moomaw, C. J., Woo, D., Adeoye, O., Flaherty, M. L., Khatri, P., Ferioli, S., De Los Rios La Rosa, F., et al. (2012). Age at stroke: Temporal trends in stroke incidence in a large, biracial population. Neurology, 79(17), 1781-1787.

34. Yakhkind, A., McTaggart, R. A., Jayaraman, M. V., et al. (2016). Minor stroke and transient ischemic attack: Research and practice. Front Neurol, 7, 86

35. Asahara, T., Kawamoto, A., \& Masuda, H. (2011). Concise review: Circulating endothelial progenitor cells for vascular medicine. Stem Cells, 29, 1650-1655.

36. Rauscher, F. M. (2003). Aging, progenitor cell exhaustion, and atherosclerosis. Circulation, 108, 457-463.

37. Heiss C, Keymel S, Niesler U, Ziemann J, Kelm M, Kalka C (2005).Impaired progenitor cell activity in age-related endothelial dysfunction. In: $J$ Am Coll Cardiol, 45: Elsevier Masson SAS; 2005: 1441-1448.

38. Varga, Z., Flammer, A. J., Steiger, P., Haberecker, M., Andermatt, R., Zinkernagel, A. S., Mehra, M. R., Schuepbach, R. A., Ruschitzka, F., \& Moch, H. (2020). Endothelial cell infection and endotheliitis in COVID-19. Lancet, 395(10234), 1417-1418.

39. Scheubel RJ, Zorn H, Silber R-E, Kuss O, Morawietz H, Holtz J, Simm A (2003).Age-dependent depression in circulating endothelial progenitor cells inpatients undergoing coronary artery bypass grafting. In: J Am Coll Cardiol. vol. 42; 2003: 2073-2080.

40. Altabas V, Altabas K, Kirigin L (2016). Endothelial progenitor cells (EPCs) in ageing and age-related diseases: How currently available treatment modalities affect EPC biology, atherosclerosis, and cardiovascular outcomes. In: Mechanisms of Ageing and Development. Elsevier Ireland Ltd; 2016: 1-14.

41. Williamson, K. A., Hamilton, A., Reynolds, J. A., Sipos, P., Crocker, I., Stringer, S. E., \& Alexander, Y. M. (2013). Agerelated impairment of endothelial progenitor cell migration correlates with structural alterations of heparan sulfate proteoglycans. Aging Cell, 12, 139-147.

42. Martí-Fàbregas, J., Crespo, J., Delgado-Mederos, R., MartínezRamírez, S., Peña, E., Marín, R., Dinia, L., Jiménez-Xarrié, E., Fernández-Arcos, A., Pérez-Pérez, J., et al. (2013). Endothelial progenitor cells in acute ischemic stroke. Brain Behav, 3, 649-655.

43. Fadini, G. P., Losordo, D., \& Dimmeler, S. (2012). Critical reevaluation of endothelial progenitor cell phenotypes for therapeutic and diagnostic use. Circulation Research, 110, 624-637.

44. Stauffer, B. L., MacEneaney, O. J., Kushner, E. J., Cech, J. N., Greiner, J. J., Westby, C. M., \& De Souza, C. A. (2008). Gender and endothelial progenitor cell number in middle-aged adults. Artery Research, 2, 156-160.

45. Paschalaki, K. E., Starke, R. D., Hu, Y., Mercado, N., Margariti, A., Gorgoulis, V. G., Randi, A. M., \& Barnes, P. J. (2013). Dysfunction of endothelial progenitor cells from smokers and chronic obstructive pulmonary disease patients due to increased DNA damage and senescence. Stem Cells, 31, 2813-2826.

46. Menegazzo L, Albiero M, Avogaro A, Fadini GP (2012) Endothelial progenitor cells in diabetes mellitus. In: BioFactors, $38: 194-202$. 
47. Delva P, Degan M, Vallerio P, Arosio E, Minuz P, Amen G, Di Chio M, Lechi A (2007). Endothelial progenitor cells in patients with essential hypertension J Hypertens 25; 2007: 127-132.

48. Du, F., Zhou, J., Gong, R., Huang, X., Pansuria, M., Virtue, A., Li, X., Wang, H., \& Yang, X.-F. (2012). Endothelial progenitor cells in atherosclerosis. Front Biosci (Landmark Ed), 17, 2327-2349.

49. Sandhu, K., Mamas, M., \& Butler, R. (2017). Endothelial progenitor cells: Exploring the pleiotropic effects of statins. World Journal of Cardiology, 9(1), 1-13.

50. Francescone III RA, Faibish M, Shao R (2011).A Matrigel-based tube formation assay to assess the Vasculogenic activity of tumor cells. In: JoVE. 2011: 1-4.

51. Khoo CP, Micklem K, Watt SM (2011).A comparison of methods for quantifying angiogenesis in the Matrigel assay in vitro. In: Tissue Engineering Part C: Methods, 17:895-906.

52. Guan, X. M., Cheng, M., Li, H., et al. (2013). Biological properties of bone marrow-derived early and late endothelial progenitor cells in different culture media. Molecular Medicine Reports, 8(6), $1722-1728$.

53. Hur, J., Yoon, C. H., Kim, H. S., Choi, J. H., Kang, H. J., Hwang, K. K., Oh, B. H., Lee, M. M., \& Park, Y. B. (2004). (2004). Characterization of two types of endothelial progenitor cells and their different contributions to Neovasculogenesis [in English]. Arteriosclerosis, Thrombosis, and Vascular Biology, 24(2), 288293.

54. Parham, K. A., Pitson, S. M., \& Bonder, C. S. (2014). Regulation of EPCs: The gateway to blood vessel formation. New Journal of Science, 2014:1-16.

55. Critser, P. J., \& Yöder, M. C. (2010). Endothelial colony-forming cell role in neoangiogenesis and tissue repair. Current Opinion in Organ Transplantation, 15, 68-72.

56. Chang EI, Loh SA, Ceradini DJ, Chang EI, Lin Se, Bastidas N, Aarabi S, Chan DA, Freedman ML, Giaccia AJ et al (2007). Age decreases endothelial progenitor cell recruitment through decreases in hypoxia-inducible factor 1 Stabilization During Ischemia. In: Circulation. vol. 116; 2007: 2818-2829.

57. Baraniak, P. R., \& McDevitt, T. C. (2010). Stem cell paracrine actions and tissue regeneration. Regenerative Medicine, 5(1), 121-143.

58. Esquiva, G., Grayston, A., \& Rosell, A. (2018). Revascularization and endothelial progenitor cells in stroke. American Journal of Physiology. Cell Physiology, 315(5), C664-C674.
59. Acosta, S. A., Lee, J. Y., Nguyen, H., Kaneko, Y., \& Borlongan, C. V. (2019). Endothelial progenitor cells modulate inflammationassociated stroke Vasculome. Stem Cell Reviews and Reports, 15(2), 256-275.

60. Sobrino, T., Hurtado, O., Moro, M. A., Rodriguez-Yanez, M., Castellanos, M., Brea, D., Moldes, O., Blanco, M., Arenillas, J. F., Leira, R., et al. (2007). The increase of circulating endothelial progenitor cells after acute ischemic stroke is associated with good outcome. Stroke, 38, 2759-2764.

61. Cuadrado-Godia, E., Regueiro, A., Núñez, J., Díaz-Ricard, M., Novella, S., Oliveras, A., Valverde, M. A., Marrugat, J., Ois, A., Giralt-Steinhauer, E., et al. (2015). Endothelial progenitor cells predict cardiovascular events after Atherothrombotic stroke and acute myocardial infarction. A PROCELL substudy. PLOS ONE, 10, e0132415-e0132413.

62. Bogoslovsky T, Spatz M, Chaudhry A, Maric D, Luby M, Frank J, Warach S (2011).Circulating CD133+CD34+ progenitor cells inversely correlate with soluble ICAM-1 in early ischemic stroke patients. In: J Transl Med. Vol. 9: BioMed Central Ltd; 2011: 145.

63. T Bogoslovsky MD P, BA AC, PhD LL, PhD DM, PhD ML, MD MS, J Frank MS MD, S Warach MD P (2010).Endothelial progenitor cells correlate with lesion volume and growth in acute stroke. In: American Academy of Neurology. Vol. 75: AAN Enterprises; 2010: 2059-2062.

64. Sobrino T, Pérez-Mato M, Brea D, Rodríguez-Yáñez M, Blanco M, Castillo J (2012).Temporal profile of molecular signatures associated with circulating endothelial progenitor cells in human ischemic stroke. J Neurosci Res. 2012: N/a-n/a.

65. Fan, Y., Shen, F., Frenzel, T., Zhu, W., Ye, J., Liu, J., Chen, Y., Su, H., Young, W. L., \& Yang, G.-Y. (2009). Endothelial progenitor cell transplantation improves long-term stroke outcome in mice. Ann Neurol, 67, 488-497.

66. Fang, J., Guo, Y., Tan, S., Li, Z., Xie, H., Chen, P., Wang, K., He, Z., He, P., Ke, Y., Jiang, X., \& Chen, Z. (2019). Autologous endothelial progenitor cells transplantation for acute ischemic stroke: A 4-year follow-up study. Stem Cells Translational Medicine, 8(1), $14-21$.

Publisher's Note Springer Nature remains neutral with regard to jurisdictional claims in published maps and institutional affiliations. 